Florida International University

FIU Digital Commons

FIU Electronic Theses and Dissertations

University Graduate School

$3-4-2020$

\title{
Innovation Diffusion Theory and Social Embeddedness - A New Perspective
}

Xuan Tan

Florida International University, xtan004@fiu.edu

Follow this and additional works at: https://digitalcommons.fiu.edu/etd

Part of the Management Information Systems Commons

\section{Recommended Citation}

Tan, Xuan, "Innovation Diffusion Theory and Social Embeddedness - A New Perspective" (2020). FIU Electronic Theses and Dissertations. 4534.

https://digitalcommons.fiu.edu/etd/4534

This work is brought to you for free and open access by the University Graduate School at FIU Digital Commons. It has been accepted for inclusion in FIU Electronic Theses and Dissertations by an authorized administrator of FIU Digital Commons. For more information, please contact dcc@fiu.edu. 


\section{FLORIDA INTERNATIONAL UNIVERSITY}

Miami, Florida

\section{INNOVATION DIFFUSION THEORY AND SOCIAL EMBEDDEDNESS-A NEW PERSPECTIVE}

A dissertation submitted in partial fulfillment of

the requirements for the degree of

DOCTOR OF PHILOSOPHY

In

BUSINESS ADMINISTRATION

by

Xuan Tan 
To: Dean Joanne Li

College of Business

This dissertation, written by Xuan Tan, and entitled Innovation Diffusion Theory and Social Embeddedness - A New Perspective, having been approved in respect to style and intellectual content, is referred to you for judgment.

We have read this dissertation and recommend that it be approved.

$\begin{array}{r}\hline \text { Weidong Xia } \\ \hline \text { Min Chen } \\ \hline \text { Mido Chang } \\ \hline \text { George M. Marakas, Major Professor }\end{array}$

Date of Defense: Feb 26, 2020

The dissertation of Xuan Tan is approved.

Dean Joanne Li
College of Business

Andrés G. Gil

Vice President for Research and Economic Development and Dean of the University Graduate School

Florida International University, 2020 
(C) Copyright 2020 by Xuan Tan

All rights reserved. 


\section{DEDICATION}

I dedicate this thesis to my family and friends. Without their patience, understanding, support, and most of all love, the completion of this work would not have been possible. 


\section{ACKNOWLEDGMENTS}

I thank the members of my committee: Prof. Weidong Xia, Prof. Min Chen, and Prof. Mido Chang for their patience, and guidance. Their directions and suggestions have been most appreciated. Prof. George M. Marakas was particularly helpful in guiding me toward a final completion of the thesis. Without their support, I could not have finished the dissertation so smoothly. 


\begin{abstract}
OF THE DISSERTATION
INNOVATION DIFFUSION THEORY AND SOCIAL EMBEDDEDNESS-A NEW

PERSPECTIVE

by

Xuan Tan
\end{abstract}

Florida International University, 2020

Miami, Florida

Professor George M. Marakas, Major Professor

This study focuses on the impact of social embeddedness on the diffusion and adoption of innovations. Historically, the primary factors influencing the adoption and diffusion of an innovation have been the perception of its' relative advantage to other technologies, its' perceived compatibility to previous innovations, and the degree to which the innovation is perceived to be difficult to use or understand (complexity). The additional characteristics of observability and trialability have been shown to be less important. However, with the effect of social embeddedness, this situation has likely changed. Trialability and observability, may outweigh the importance of the first three characteristics.

The goal of this study is to explore this phenomenon by reexamining the relative weight of the five characteristics of innovation with regard to innovations under the influence of social embeddedness. Therefore, provide a more informed way of looking at innovation diffusion theory. The results of this study found that social embeddedness have positive 
and significant effects towards all perceived characteristics of innovation. However, the ease of use was not as important if the adoption intention was for an emerging innovation; while for an enabling innovation, ease of use become important and people are willing to sacrifice the compatibility of the innovation. Results also found that observability and trialability were important factors to consider for emerging innovation, but they are less of concern when it comes to enabling innovation. Relative advantage has been consistently showing significant effects regardless of the type of innovation. The study contributes to both theory and practice by furthering the understanding of Innovation Diffusion Theory and by helping innovation providers develop better strategies when they advertise their products. 


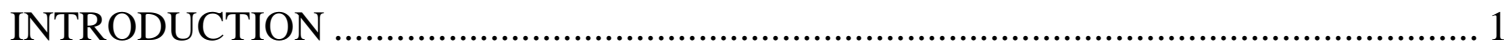

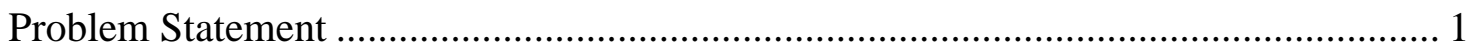

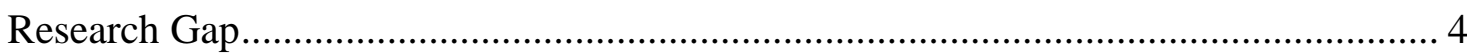

Research Questions …………………………………….................................... 7

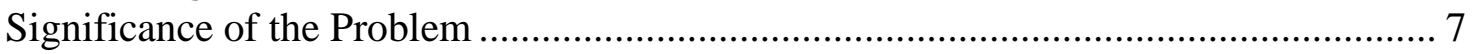

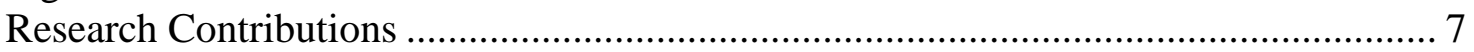

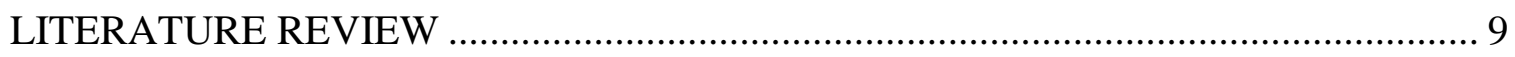

Overview of Innovation Diffusion Theory .............................................................. 9

Overview of Theory of Planned Behavior .......................................................... 14

Overview of Social Embeddedness .................................................................... 16

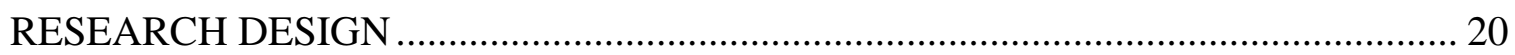

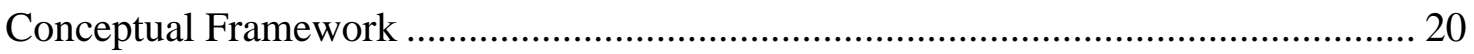

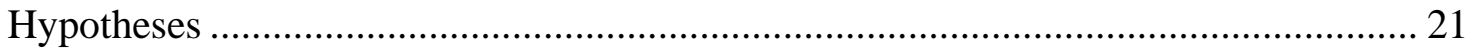

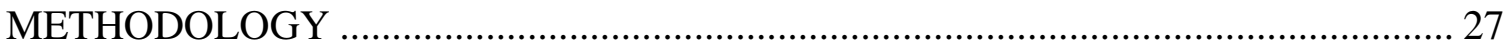

Participants and Procedure .................................................................................. 27

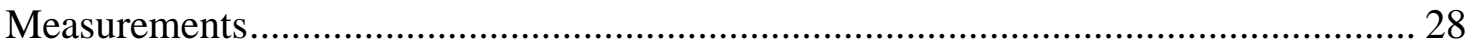

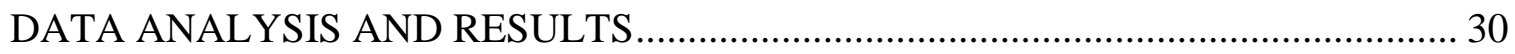

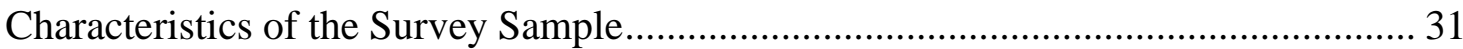

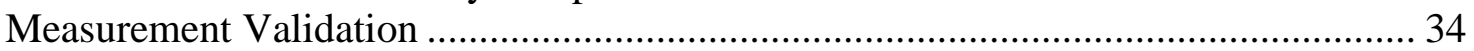

Test of the Structural Model - Emerging Technology ............................................. 38

Test of the Structural Model - Enabling Technology …….............................................. 47

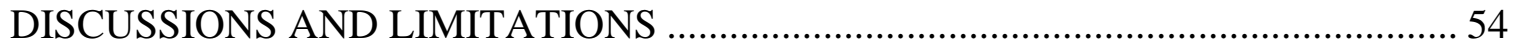

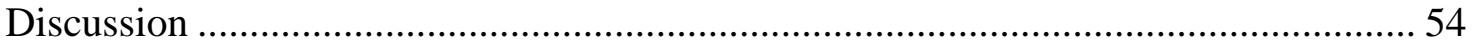

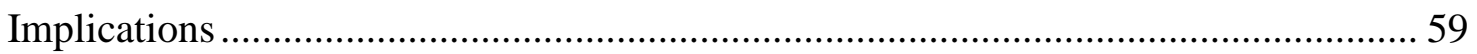

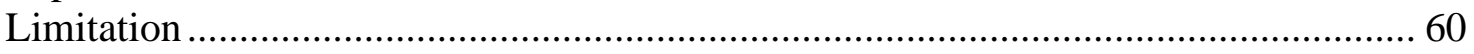

CONCLUSION

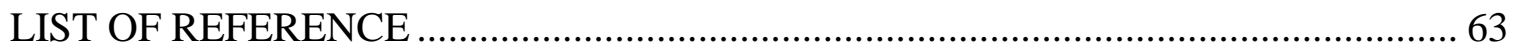

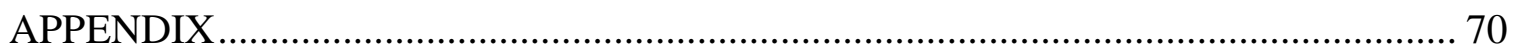

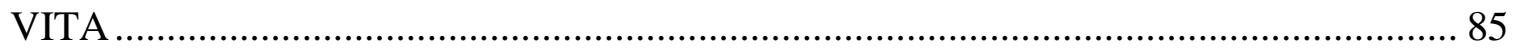




\section{LIST OF TABLES}

TABLE

PAGE

Table 1. Characteristics of the Sample …………….................................................... 32

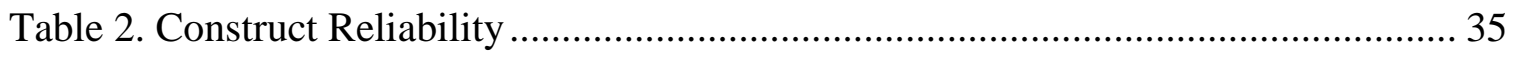

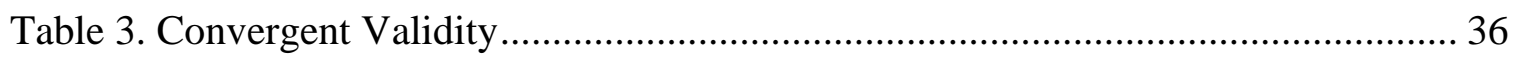

Table 4. Discriminant Validity for Reflective Constructs .............................................. 36

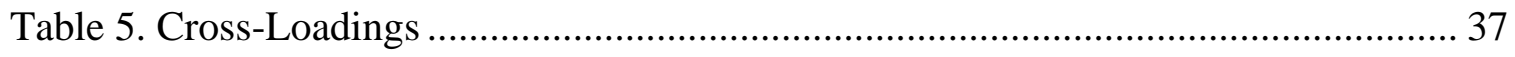

Table 6. VIF Statistics for Formative Indicators .......................................................... 38

Table 7. R-Squared - Emerging Technology …………............................................... 40

Table 8. Effect Overview - Emerging Technology ………………………………….... 41

Table 9. Summary of Hypotheses - Emerging Technology ............................................. 42

Table 10. R-Squared - Enabling Technology ………………........................................ 48

Table 11. Effect Overview - Enabling Technology ......................................................... 49

Table 12. Summary of Hypothesis - Enabling Technology ........................................... 50 


\section{LIST OF FIGURES}

\section{FIGURE}

PAGE

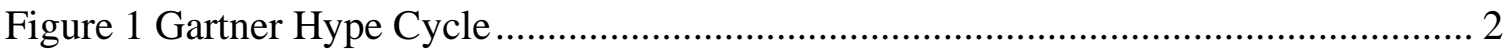

Figure 2 Five-Step Decision Making Process of Diffusion .......................................... 10

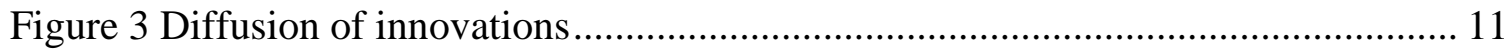

Figure 4 Main Variables of the Theory of Planned Behavior......................................... 14

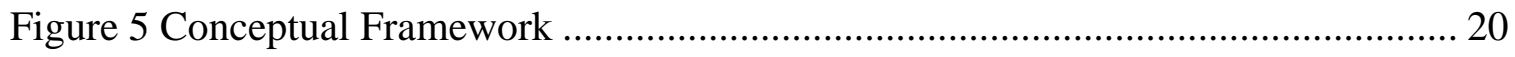

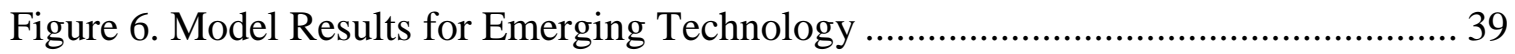

Figure 7. Model Results for Enabling Technology .................................................... 47 


\section{INTRODUCTION}

\section{Problem Statement}

Historically, among the five characteristics of innovation diffusion theory: relative advantage, compatibility, complexity, trialability, and observability, the first three characteristics have been considered as more important than the latter two on the successful diffusion of an innovation. However, with the bloom of social media, this situation may have changed. People no longer ignore the importance of the trialability and observability of certain innovations, and trialability and observability may even outweigh the importance of the first three characteristics.

Amara's Law states that: "we tend to overestimate the effect of a technology in the short run and underestimate the effect in the long run" (Ratcliffe, 2016; Searls, 2012). The Law has been described as best illustrated by the Gartner Hype Cycle (Gartner, 1995; Linden \& Fenn, 2003). This cycle (Gartner, 1995; Linden \& Fenn, 2003) is developed by the American research, advisory and information technology firm Gartner. According to Gartner (Gartner, 1995; Linden \& Fenn, 2003), the life cycle of technologies such as the Internet of Things and quantum computing progresses through several stages. The emerging technology starts with a technological breakthrough, a proof-of-concept, or prototypes, which triggers public interest in the new technology (Innovation Trigger). The new technology is still at the experimental stage and no viable business applications have been developed yet. Typically, the innovation trigger is followed by increased publicity. Overemphasized success cases and stories of selected adopters tend to neglect the technology's technical limitations. In additional to survival bias, the benefits may 
have been exaggerated. Then the technology enters the period of unrealistic expectations (Peak of Inflated Expectations). Unrealistic expectations towards the technology and the herding behavior to follow the fad made innovators to adopt the technology at this stage. Soon the majority of the first adopters finds out that the technology is still at early stage and there is no proven benefits, they fail to extract value from their investment and the initial hype is followed by disappointment (Trough of Disillusionment). While, some of the developers and adopters exit, some continue to improve the technology. Gradually, updated versions and new instances of the technology shows that the technology can benefit the adopters, public gain the renewed interest and spawn a new generation of adopters (Slope of Enlightenment). Their success provides proof that the technology is viable and generates benefits, thus the general public (or the majority adopters) began to adopt the technology (Plateau of Productivity) (Gartner, 1995; Linden \& Fenn, 2003). A general illustration of the Gartner Hype Cycle is shown below in Figure 1.

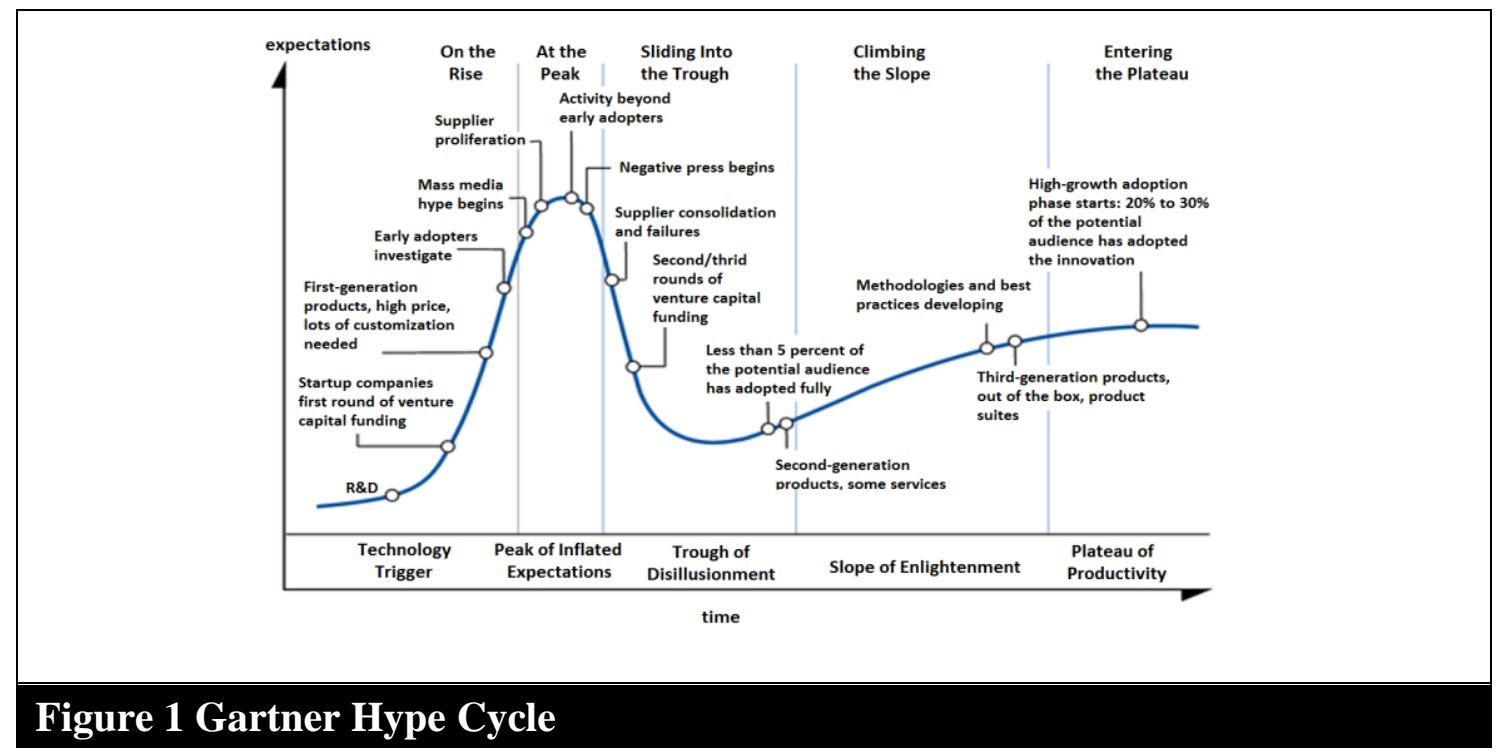

Source: (Gartner, 1995; Linden \& Fenn, 2003; O'Leary, 2008) 
The iPhone $\mathrm{X}$ release serves as an excellent example of this cycle. Long before the actual product launch, social media hosted much discussion about the product, and many made the decision to adopt the iPhone $\mathrm{X}$ without ever having seen the product firsthand simply based on the product-related specifications and videos available online. People made up their minds after viewing how other people used the iPhone (observability); or test with iPhone (trialability). Intention to adopt the innovation is developed based on these two innovation diffusion characteristics. During this same period, the relative advantage, complexity, and compatibility of the innovation played a minor role in the decision to adopt.

In this sense, simply considering relative advantage, compatibility, complexity, trialability, and observability together as a unified predictor of adoption of an innovation appears to be no longer tenable or appropriate. As such, it seems relevant to consider how adoption intention before product launch transfers to actual adoption after product launch given the ubiquitous nature of social media.

It seems clear, with the increased publicity of an innovation through social media, the trialability and observability characteristics should become more salient. In contrast, relative advantage, compatibility, and complexity become less of a consideration when it comes into a decision given the absence of the actual product.

The removal of the iPhone $3.5 \mathrm{~mm}$ earphone jack can serve as an example. Initially, removing the $3.5 \mathrm{~mm}$ earphone jack would appear to affect backward compatibility. Despite this, with the massive number of iPhone adopters, this minor change in the design began to immediately change user behavior by increasing the use (and likely, 
sales) of Bluetooth earphones. In this example, compatibility becomes less important than in the past, or at least of less consideration when it comes to a decision whether to adopt the new innovation. Given these scenarios, the interpretation of the innovation diffusion theory may need to be updated to be in better correspondence with the fast-changing social media-driven environment.

\section{Research Gap}

Diffusion is a social process that occurs among people in response to learning about an innovation (Rogers Everett, 1995). The diffusion process consists of four key elements: innovation, communication channels, time, and the social system (Mahajan, 1985).

Factors that influence the diffusion of innovation involves three general sets of variables: each innovation's set of pros and cons, or attributes; the characteristics of the adopters; and the larger social and political context (Dearing \& Cox, 2018).

Since the development of innovation diffusion theory in 1962 by Rogers, there are different genres of research aimed to explain and predict user acceptance and time to adoption of an innovation. It is not uncommon to include the perceived characteristics of an innovation as key independent variables (Agarwal \& Prasad, 1997). The perceived characteristics of an innovation include considering relative advantage, compatibility, complexity, observability and trialability.

Relative advantage is the degree to which the innovation is perceived as better than the innovation it supersedes. Compatibility represents the degree to which the innovation is perceived as being consistent with existing innovations. Complexity, or sometimes referred as simplicity, is the degree to which the innovation is perceived as difficult to 
understand and use. Observability is the degree to which the results of the innovation are visible to others and the trialability is the degree to which the innovation can be tried without commitment and minimal investment (Rogers, 2003).

Previous literature considers relative advantage, compatibility, and complexity as more powerful factors when making their decisions to adopt, while observability and trialability have been generally viewed as less important (Tornatzky \& Klein, 1982). Given the epidemic growth of social media, this may no longer hold true. There is a lack of empirical evidence within the extant literature regarding the relative effects of the five characteristics in influencing peoples' decision making in a digital age. As such, this study aims to fill this research gap by re-examining the relative importance of the five characteristics when it comes to a technology/innovation adoption decision given a person's social embeddedness under social media settings. The concept of social embeddedness, originally proposed by Granovetter (1992), refers to the extent an individual's action is materially driven by the normative assumptions they share with the individuals they interact.

In addition, previous literature has mainly focused on how the perceived attributes of innovation affect the adoption and diffusion of innovation as a whole while ignoring the effects of time, i.e. people may change their mind during the process of transferring from adoption intention to actual adoption (Rogers Everett, 1995). This condition can also be seen in the Gartner Hype Cycle (Gartner, 1995; Linden \& Fenn, 2003) as people may make changes in their decisions on whether or not to adopt an innovation according to positive or negative reviews on the innovation through mass media. Valente (1996) 
expanded the social model proposed by Ryan and Gross (Ryan \& Gross, 1943) by looking specifically into social networks and individual's personal network. Valente believes these network thresholds can be used to vary the definition of behavioral contagion, to predict the pattern of diffusion of innovations, and to identify opinion leaders and followers in order to understand the two-step flow hypothesis better. The two-step flow hypothesis states that the media inform opinion leaders who, in a second step, influence opinion followers (Katz, 1957; Weimann, 1982). More recent study has also provided evidence of a social network's influence on innovation diffusion. Wear (2008) showed that significantly more innovation appears in communities with stronger inter-personal networks, particularly in regional and rural areas.

Beyond re-examining the relative importance of the perceived characteristics of innovation, this study also takes a step further and takes the time between adoption intention and actual adoption attention action into account. Few studies have focused on how the perceived characteristics of innovation interact with social factors, and consequently, how this interaction may affect customers actual attention to adopt. In this study, attention is focused on how social embeddedness may affect the adoption intention before product launch and actual adoption action after product launch, especially in a digital age, where one can get information of certain technology/innovation easily. This study aims to fill the research gap by examining how observability and trialability before and after product launch will affect the relationship between adoption intention and adoption action. Therefore, we have the following research questions: 


\section{Research Questions}

1. What is the relative contribution of relative advantage, compatibility, complexity, trialability, and observability to adoption intention and actual adoption in the presence of social embeddedness?

2. How does observability and trialability before and after product/innovation launch and social embeddedness affect innovation diffusion?

\section{Significance of the Problem}

Re-examining the relative weight of the five perceived characteristics of innovation will provide a more informed way of looking at innovation diffusion theory. As innovation diffusion theory is widely applied to areas such as marketing, information systems, and the health care sector, it is important for us to continually revalidate the theory, as well as discover how can we refine it. Apart from this, the process of turning innovation adoption intention before product/innovation launch to actual innovation adoption after product/innovation launch has been something of a black box. Uncovering the veil of the process may help us better understand consumer behavior as well as enhance the understanding of the theory of innovation diffusion.

\section{Research Contributions}

This study bears both theoretical and practical implications. The findings of this study provide us with insights into the extant understanding of innovation diffusion theory. 
This study is also beneficial to practice as the impact of observability and trialability may help product/innovation providers develop better strategies when they advertise their product/innovation and enhance the innovation adopters' experience to promote more successful transformation from innovation adoption intention to actual innovation adoption. 


\section{LITERATURE REVIEW}

\section{Overview of Innovation Diffusion Theory}

Diffusion of innovation theory describes the process through which new ideas, practices, or technologies are spread into a social system (Rogers, 2003). Rogers was the most prominent developer of diffusion of innovation theory in the literature and his book, Diffusion of Innovations, was first published in 1962 and is now in its fifth edition (Rogers, 2003). Rogers' theory of innovation diffusion has laid the foundation for many of the studies in this area along with the development of a variety of dependent variables related to innovation diffusion such as the acceptance of innovation, adoption of technology, diffusion rate, and diffusion speed. Diffusion of innovation theory has since spread to many different fields and developed into diverse streams with its tenets (Murray, 2009).

Diffusion of innovation theory holds that innovation diffusion is "a general process, not bound by the type of innovation studied, by who the adopters [are], or by place or culture" (Rogers, 2004, p. 16). Rogers defines innovation as "an idea, practice, or object that is perceived as new by an individual or other unit of adoption”. Rogers and Shoemaker (1971) emphasized that whether the "idea" or "object" is far from its first use or discovery does not change its definition as innovation. How a person reacts to the idea or object determines the perceived newness. "If the idea seems new to the individual, it is an innovation" (Rogers, 2003, p. 12).

Diffusion occurs through a five-step decision-making process, including knowledge, persuasion, decision, implementation and confirmation (Rogers Everett, 1995). 


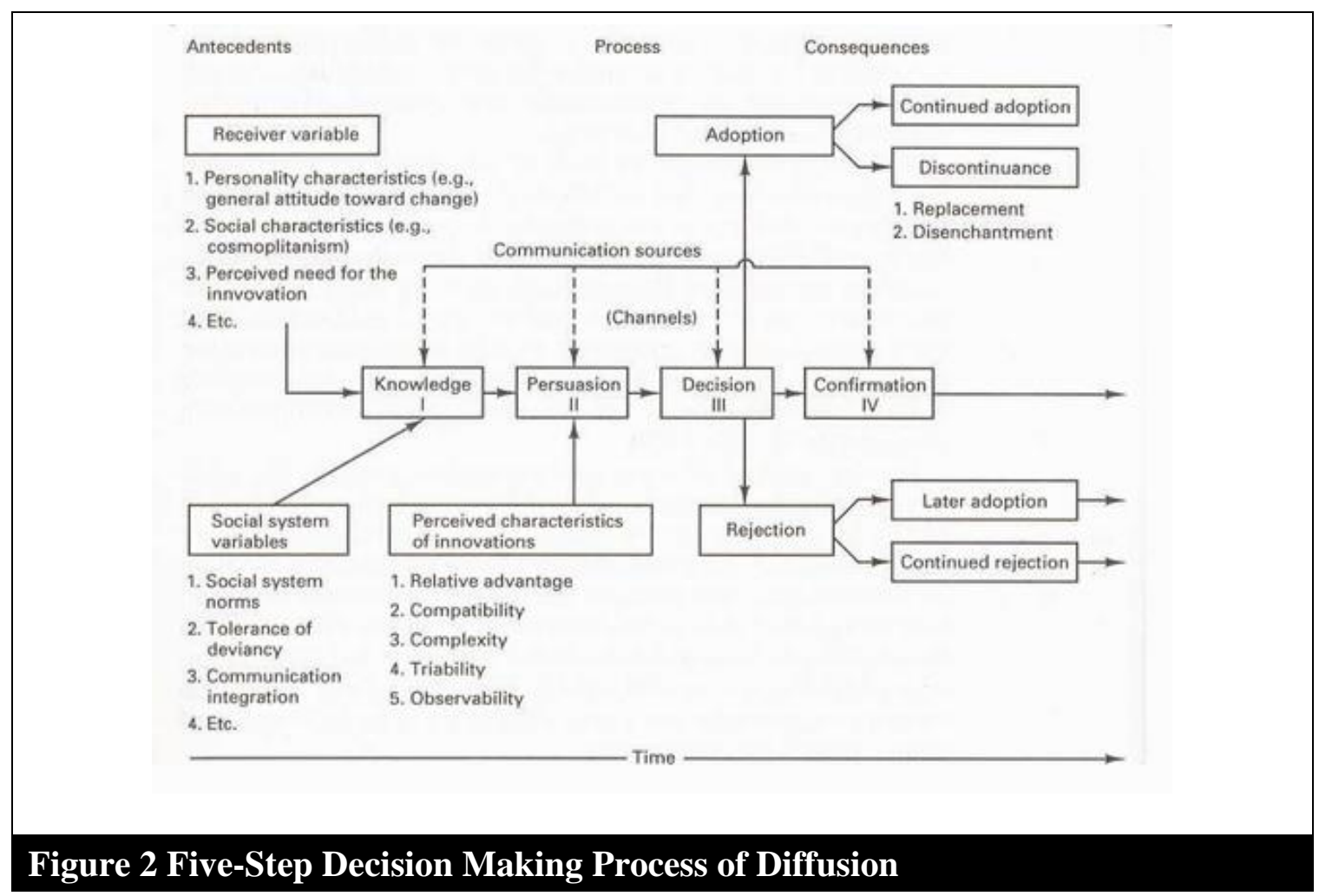

Source: (Rogers Everett, 1995)

As shown in Figure 2 above, the knowledge stage is when a person gets to know a new idea, product, or innovation with no prior knowledge. The individual then progresses to find out more related information or details on the innovation in the persuasion stage.

After the individual understands the innovation and weighs the advantages and disadvantages of innovation, the individual will decide whether or not to adopt the innovation (the decision stage). Next, in the implementation stage, the individual determines the how useful the innovation is and finally, in confirmation stage, the individual executes the decision (Rogers Everett, 1995).

The key elements considered in innovation diffusion theory include innovation, adopters, communication channels, time and the social system (Rogers, 2003). Innovation, as previously mentioned, is a broad category, and can be any idea, practice, or object that is 
perceived as new. Adopters are the minimal unit of analysis, they can be individuals, groups, or organizations. Communication channels are the infrastructure for to allow innovation to diffuse from one to another. Time is necessary for an innovation to be adopted or diffused. The social system is the combination of both external and internal influences including mass media, surfactants, organizational or governmental mandates, social relationships, and distance from opinion leaders (Rogers, 2003).

According to Rogers (1995) adoption of a new technology by individuals or firms tends to follow an approximate bell shaped distribution as shown in Figure 3.

\section{Diffusion of innovations}

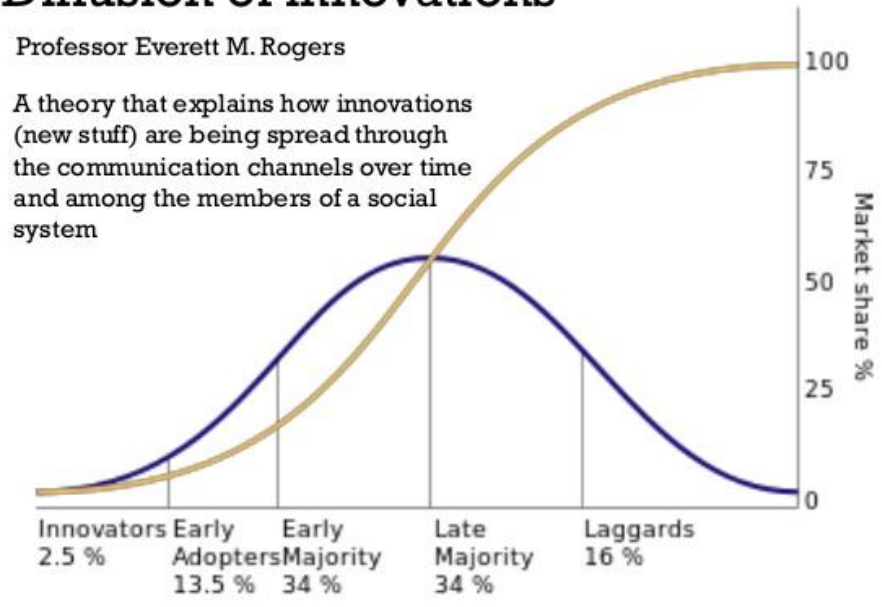

Figure 3 Diffusion of innovations

Source: (Rogers Everett, 1995)

Rogers (1995) argues that the adoption of new technology follows the bell shaped distribution because of the cumulative influence upon potential adopters from peer networks. In business terms, this means that the documented profitability and efficiency 
gains of early adopters would make the following followers to make a choice between follow to catch up or in a disadvantageous position (Porter, 1985). Using the properties of the bell shaped distribution (The empirical rule, or the three sigma rule, which determines the percentage of values around the mean for the standard deviation width of 1 sigma, 2 sigma and 3 sigma to analyze the bell shaped curve statistical data), Rogers (1995) proposed the following five categories of technology adopters: ${ }^{1}$ Innovators (the first $2.5 \%$ ), early adopters (the following $13.5 \%$ ), early majority (the next $34.0 \%$ ), late majority (another $34.0 \%$ after early majority), and laggards (the last 16.0\%). Innovators are the first to adopt a new technology and often adopt due to excitement and novelty. The second group, early adopters, though not as risk seeking as the innovators, are those who appraise the innovation's advantages and disadvantages but still are willing to deal with relatively high levels of uncertainty. Typically, this category has the advantage of observing and learning from the successes and failures of innovators and, as such opinion leaders and trend setters tend to adopt at this time. The role of early adopters is, therefore, pivotal. Their success will often trigger mass adoption (early majority), their failure usually marks the end of the new technology. The early majority will join the adoption process at this stage as they perceive the risks have been mitigated while the benefits of the adoption are still relatively high. They may also join the adoption process because they feel pressured to do so due to their social environment. Collectively, these three groups represent approximately $50 \%$ of potential adopters. The remaining $50 \%$ is

\footnotetext{
${ }^{1}$ The classification is only applicable in the case for successful technological innovations. There are many innovations that fail to go beyond the innovator or early innovator stage.
} 
identified by the last two categories of adopters: late majority and laggards. The former reflects adopters that invest in the new technology as a result of strong peer pressure, while the laggards are less susceptible to social pressure and feel free to take their time (Dearing \& Cox, 2018; Rogers Everett, 1995).

Numerous studies have attempted to explain the relationship between user perceptions, attitudes, and eventual system use, as well as factors that influence the innovation adoption and diffusion. Moore and Benbasat (1991) developed and tested measurements for perceived characteristics of innovation, and provided a useful tool for the study of innovation diffusion theories of 38-item instrument comprising eight scales. Fishbein and Ajzen (1975) attempted to illustrate the relationship between user acceptance and innovation adoption. Research has also been focused on suggesting analytical models that describe and forecast the diffusion of innovation with the main thread of diffusion models being based on the framework developed by Bass (1969). This model suggests the probability that an individual will adopt the innovation - given that the individual has not yet adopted it- is linear with respect to the number of previous adopters (Peres, Muller, \& Mahajan, 2010). Besides developing instruments, connecting with other theories such as the theory of planned behavior, and validating the theories empirically, recent literature also suggests additional mechanisms for innovation diffusion. Peres, Mahajan and Muller (2010) suggested that signals and network externalities may also have an impact on innovation diffusion. Signals are defined as any market information other than personal recommendation that can be used by a potential adopter to make an adoption decision while network externality refers to the observation that the utility of some products or 
services may increase as more consumers adopt the new product (Mahajan, 1985; Peres et al., 2010).

\section{Overview of Theory of Planned Behavior}

The Theory of Planned Behavior (TPB) (Ajzen, 1985), extending the Theory of Reasoned Action (TRA) (Ajzen \& Fishbein, 1980; Fishbein \& Ajzen, 1975), posits that an individual's attitude towards a behavior, her subjective norm, and perceived behavioral control combine to form her intention to perform a particular behavior, and in turn, lead to that behavior. By taking into consideration a person's unequivocal perception of control, the theory expands on the application of TRA to refer not only to merely voluntary but also to intrinsic behaviors. This is particularly important in the case of innovation diffusion which often involves an adopter's attitude towards the innovation as well as the environment adopter lives in.

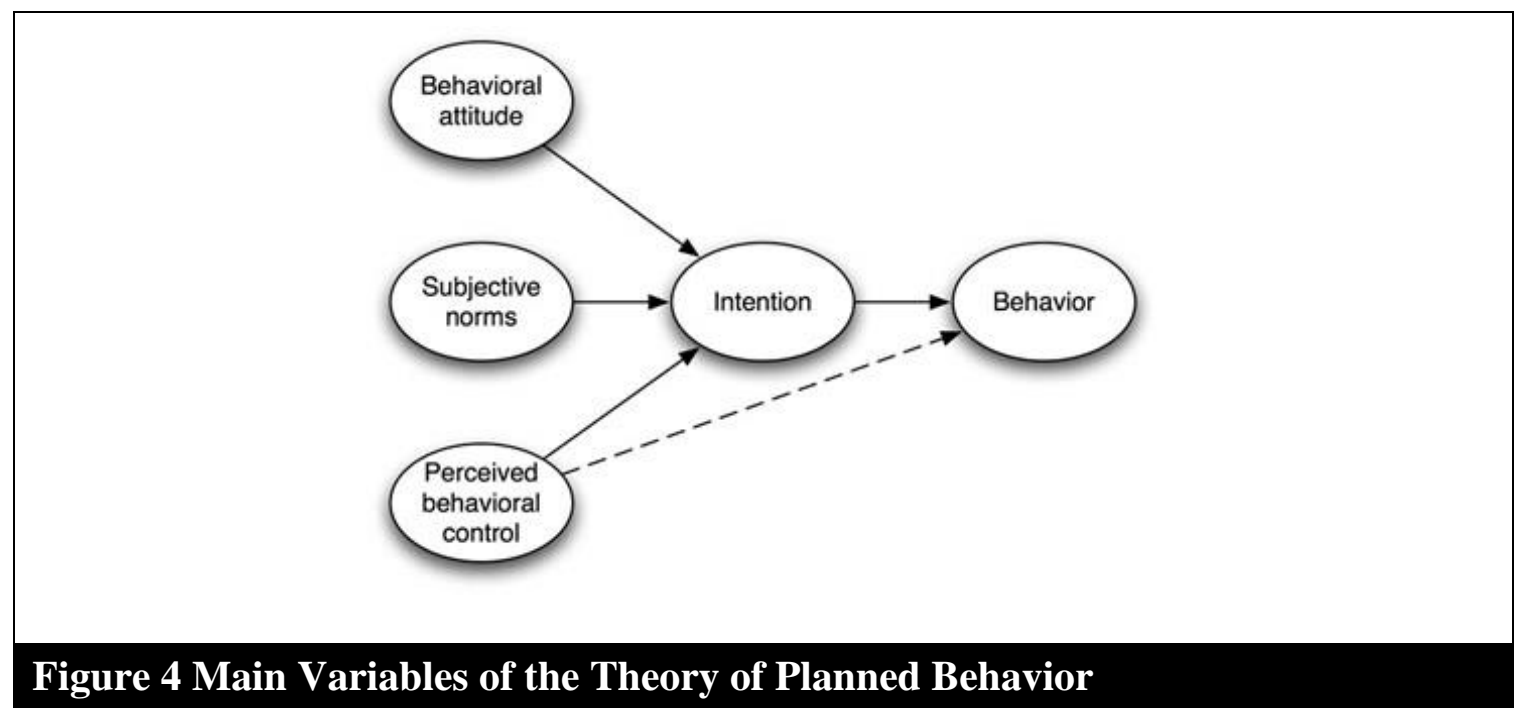

Source: (Fishbein \& Ajzen, 1975) 
Attitude toward the behavior is defined as the person's feeling about the behavior. The feeling is determined based on the assessment of his/her beliefs towards the action of the behavior and his/her desirability of the corresponding consequences. Formally, overall attitude can be assessed as the total of one's assessments towards the consequences of certain behavior. Subjective norm is defined as one's perception of how others that are important to him/her think they should behave. Overall subjective norm can be summed as the total of one's motivation and perception assessments of the ones he/she thinks important. Behavioral control is defined as the degree of difficulty to perform a behavior (Ajzen, 1985).

TPB thinks that one's control towards his/her behavior lies on the behaviors that can be easily performed. Ajzen has suggested that the link between behavior and behavioral control outlined in the TPB model should be between behavior and actual behavioral control. But the difficulty to measure the actual behavior control has led the model to measure the perceived behavior control as a proxy (Furneaux, 2019).

The theory of planned behavior has received considerable attention in the literature. The Theory of Reasoned Action (Fishbein \& Ajzen, 1975) is a general theory applicable to an array of behaviors, including the forces which influence the use of IT, and the adoption and diffusion of an innovation. Thus, certain concepts of diffusion research could be used to apply the theory of reasoned action, or the theory of planned behavior. For example, Moore and Benbasat integrated the innovation of diffusion theory and the reasoned action models to predict utilization of information technology by end-users (Moore \& Benbasat, 1996). Their research undertakes such a study by using diffusion research to provide a 
basis for identifying a set of generic perceptions or beliefs which could affect one's attitude towards using IT. It then integrates these perceptions with several constructs from TRA to develop and test a model which helps explain individual use of end-user IT (Moore \& Benbasat, 1996).

\section{Overview of Social Embeddedness}

Granovetter (1992) pointed out that:

$$
\begin{aligned}
& \text { "Embeddedness" refers to the fact that economic action and } \\
& \text { outcomes, like all social action and outcomes, are affected by } \\
& \text { actors' dyadic (pairwise) relations and by the structure of the overall } \\
& \text { network of relations. As a shorthand, I will refer to these as the } \\
& \text { relational and the structural aspects of embeddedness. The structural } \\
& \text { aspect is especially crucial to keep in mind because it is easy to slip } \\
& \text { into "dyadic atomization," a type of reductionism. (P. 33, italics in } \\
& \text { original) }
\end{aligned}
$$

The core argument of social embeddedness is that embedded relations, in contrast to atomistic arms-length exchanges, exhibit shared norms and values, reduce the need for monitoring and control, and facilitate the transfer of information and integration of specialized knowledge and capabilities (Granovetter, 1985; Uzzi, 1997). The economic implications of social embeddedness are expected to be especially important in an innovation diffusion context, where the decision process of adoption intention to actual behavior needs to be understood. Peres et al (2010) characterize social embeddedness into two dimensions, network externalities and social signals. Network externalities refers 
to the observation that the utility of some products or services may increase as more consumers adopt the new product (Peres et al., 2010; Tucker, 2008). Social signals refers to any market information other than personal recommendation that can be used by a potential adopter to make the decision (Peres et al., 2010).

The effect of social embeddedness was examined in a strategic IS project development context. Using data from a longitudinal field study of 155 offshore IS projects managed by 22 project leaders, Rai, Maruping and Venkatesh (2009) found evidence of a relationship between project cost overruns and client satisfaction over the effects of project characteristics and agency factors. Specifically, they found that social embeddedness reduced project cost and improved client satisfaction. Rai et al. (2009) characterized social embeddedness as joint problem solving, fine-grained information transfer, and trust referring to MacNeil's review (Macneil, 1985). All of which leads to superior outcomes, when transfer, and trust-lead to superior outcomes, especially when all information cannot be codified and transferred through market mechanisms and each partner in the exchange relationship possesses significant tacit knowledge and domain specialization.

More recently, an increasing number of studies have also addressed the importance of social embeddedness using mathematical modelling. For example, Vastag and Montabon (2002) proved the role of social acculturation in journal rankings by showing that the perceived journal impact has been developed through many layers of social connectedness, of which doctoral education is one prominent factor. Benedek, Lublóy, and Vastag (2014) argued the importance of social embeddedness at mobile providers by 
examining the effects of customers' network topological properties on churn probability — the probability of a customer switching from one telecommunication provider to another. Using snow sampling, which is the only practically feasible network sampling method, this study found that social embeddedness blocks the impact of the very same marketing efforts. Moody and White (2003) focused on how social cohesion and social embeddedness is linked by developing a concept of structural cohesion based on network node connectivity. Structural cohesion is defined as the minimum number of actors needed to hold the group. A structural dimension of embeddedness is then defined as the hierarchical nesting of these cohesive structures. In their study, the social network based concept is developed based upon on Simmel (Simmel, 1950) and Durkheim (Durkheim, 2014) and methodologically grounded in classical graph theory (Cartwright, Harary, \& Norman, 1965; Harary, 1969). They implemented an algorithm for measuring embedded levels that provides an operational specification of one dimension of social embeddedness (Granovetter, 1985, 1992). Abrahamson and Rosenkopf focused on explaining why certain innovations diffuse extensively. They suggest the structure of social networks, through which potential adopters of innovations find out information about innovations, can cause such individuals to adopt an innovation. Thus, they propose that the number of network links, and the social structures can have very large effects on the extent of an innovation's diffusion amongst members of a social network community (Abrahamson \& Rosenkopf, 1997). Angst, Agarwal, Sambamurthy, and Kelley (2010) used social contagion instead of social embeddedness to study the dynamic, temporal process of the diffusion of electronic medical records in the population of U.S. hospitals. They define social contagion as the mutual influence among organizations within an 
institutional field using either direct or indirect contact mechanisms. They hypotheses that the likelihood of a hospital's decision of adopting electronic medical records is related to its susceptibility to the influence of prior adopters. They found strong effects for social proximity and significant regional effects for spatial proximity and hospital size towards the decision of adoption.

In this study, the definition of social embeddedness is adapted from multiple sources. Hultman (2004) characterizes social embeddedness into four facets: relational, structural, temporal, and institutional embeddedness. The relational embeddedness of technology adoption refers to how adoption and adoption processes are influenced by, direct and indirect relationships (Granovetter, 1992). Structural embeddedness of technology adoption refers to how adoption and adoption processes are embedded in and influenced by structural positions (Granovetter, 1992). Temporal embeddedness refers to how adoption and adoption processes are influenced by time effects, including previous and current experiences (Rosenberg, 1982; Utterback, 1994). Finally, institutional embeddedness refers to how adoption and adoption processes are embedded in and influenced by socially constructed norm systems (DiMaggio \& Powell, 1991). Reed and Selbee (2003) characterize social embeddedness into three dimensions: social connectivity, social anchoring and social continuity. Social connectivity refers to the extend an individual is linked to his/her social context. Social anchoring refers to one's values, beliefs, and life-ordering principles, especially when periodically affirmed with like-minded people. Social continuity indicates if there is an absence of social change. The extent to which an individuals within societies need depends on significant factors like age, gender, education, access to wealth, vested interest, etc (Lipset, 1959). 


\section{RESEARCH DESIGN}

Conceptual Framework

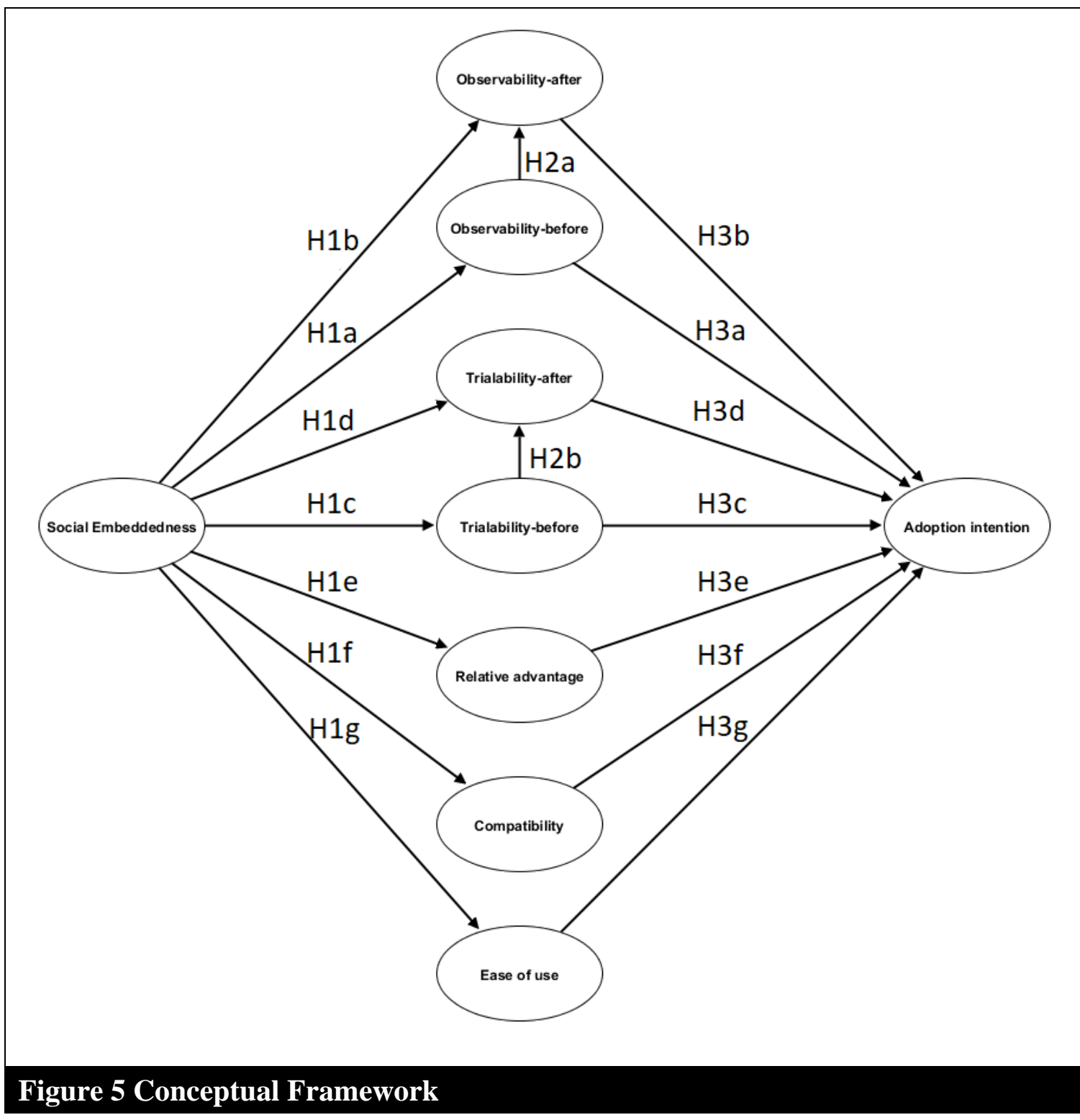




\section{Hypotheses}

Embeddedness is referred as the dependence of a phenomenon on its environment in social science. It can be the dependence of the economy or the market, a set of relationships, an organization, or an individual on its environment. It can also be defined alternatively in institutional, social, cognitive, or cultural terms (Schmidt, 2013). The social embeddedness describes how the innovation is embedded into the social network. Apple products, which can be seen everywhere, either online or offline, and can be categorized as deeply social embedded innovations. When Apple decides to launch a new product, the information and related commercial can easily penetrate to the audience, since they are deeply embedded. Trialability and observability refers to if the innovation is visible and available to experience. With a deeply embedded social network, it is not unnatural to think that Apple products will be more visible and available to the audience than those with less deeply embedded social network. Therefore, it is hypothesized that social embeddedness has a positive impact on the perceived characteristics of technology. With higher level of social embeddedness, the innovation is more penetrated and can be easily tried and observed by the consumers. Drawing on past studies, we propose that the level of social embeddedness would have positive effects on the perceived observability and perceived trialability, and finally affects the adoption intention through the perceived characteristics.

H1: Social embeddedness will have a positive impact on the perceived characteristics of Technology. 
Hla: Social embeddedness will have a positive effect on perceived observability before product launch.

HIb: Social embeddedness will have a positive effect on perceived trialability before product launch.

H1c: Social embeddedness will have a positive effect on perceived observability after product launch.

HId: Social embeddedness will have a positive effect on perceived trialability after product launch.

Rogers argued that the main drivers of the adoption are the interpersonal channels of communication (Rogers Everett, 1995). Empirical studies have also provided evidence. A study by Naseri and Elliott (2011) found that consumers who are more socially oriented would be more influenced by the pressure of two social forces, namely word-of-mouth and social signals. According to a meta-analysis done by Sultan, Farley and Lehmann, the word-of-mouth is the main deriver of innovation diffusion (Sultan, Farley, \& Lehmann, 1990). Besides the influence of social influence or social embeddedness have on adoption intention, literature has also provided support on the direction of the influence. Dickerson and Gentry mentioned that the literature often consider innovators as social integrated and as belonging to more social groups (Dee Dickerson \& Gentry, 1983). Therefore, it is reasonable to consider that the higher the level of social embeddedness, the higher the likelihood of adoption. However, different from previous studies, which considered 
social influence as parallel of the other perceived characteristics, we posit that the social embeddedness influences the adoption intention through the perceived characteristics of innovation. With the higher level of social embeddedness, consumers' opinions towards the innovation are more likely to be influenced by the opinions of the people around them.

A recent Google Pixel 3 advertisement serves as another good example. There are only two photos in the advertisement, one shot by iPhone in the night and another shot by Pixel 3 in the night. The one shot by Pixel 3 clearly performs better than the one shot by iPhone. With the deeply embedded social network, it is easy for the consumers to come to the conclusion that Pixel 3 is outperforming iPhone in taking pictures while neglecting the other shortages such as time lag in accessing the camera app etc. of Pixel 3. Similarly, we believe that other perceived characteristics would also be influenced by the social embeddedness. Thus, we proffer the following hypotheses:

H1e: Social embeddedness will have a positive effect on perceived relative advantage.

HIf: Social embeddedness will have a positive effect on perceived complexity.

H1g: Social embeddedness will have a positive effect on perceived compatibility.

The Baader-Meinhof phenomenon (Kershner, 2015), or the frequency illusion, happens when one stumble up something new, and will find him or herself hearing about it more often afterwards. The Baader-Meinhof phenomenon is true about that one may actually hear it more often, but more because one notices it more often than one previous do (Zwicky, 2005). The phenomenon explains why the perceived product observability 
before product launch would influence perceived product observability after the product launch. Therefore, if one perceives the observability before the product launch as high, it is more than likely that one will perceive the observability of the product after the launch high. Thus, we have the hypothesis $\mathrm{H} 2 \mathrm{a}$, the perceived observability before product launch will have a positive effect on the perceived observability after product launch.

H2a: The perceived observability before product launch will have a positive effect on the perceived observability after product launch.

H2b: The perceived trialability before product launch will have a positive effect on the perceived trialability after product launch.

According to the hype cycle (Gartner, 1995), the life cycle of nascent technologies goes through the several stages: The emerging technology starts with a technological breakthrough or a proof-of-concept, which triggers public interest in the new technology. The new technology is still at the experimental stage and no viable business applications have been developed yet. Typically, the innovation trigger is followed by increased publicity, which are normally stories, videos, and articles from the first test users or adopters made available through social media. The technology enters the period of unrealistic expectations. During this stage, people formulate their intention whether to adopt the innovation based on the reviews and specifications such as complexity, relative advantage, compatibility, observability and trialability of a certain product/innovation, despite no actual availability of the product/innovation. As such, we separate observability and trialability into pre- and post-product launch. Consistent with previous 
literature, we believe the observability and trialability before the product launch will have positive effects on the adoption intention

H3: The perceived characteristics of innovations will have a positive effect on the adoption intention.

H3a: The perceived observability before product launch will have a positive effect on the adoption intention.

H3b: The perceived trialability before product launch will have a positive effect on the adoption intention.

H3c: The perceived observability after product launch will have a positive effect on the adoption intention.

H3d: The perceived trialability after product launch will have a positive effect on the adoption intention.

The present study is based on Rogers' (2003) theoretical framework of the diffusion of innovations theory. Rogers' framework describes the processes through which ideas, practices or objects are communicated and thereby adopted by members of a society over time. Rogers explained how certain attributes of an innovation impact a person's choice to adopt that innovation. These innovation attributes are perceptual rather than objective realities. Various authors have described these attributes in detail and have named them perceived characteristics of innovations (PCIs) (Chiasson \& Lovato, 2001; Moore \& Benbasat, 1991; Tornatzky \& Klein, 1982; Zhu \& He, 2002). 
Weigel, Hazen, Cegielski, and Hall conducted a meta-analysis on innovation diffusion and the theory of planned behavior, and found that all the antecedents yielded with “medium" effects: compatibility $(\rho=.43)$, relative advantage $(\rho=.42)$, perceived behavioral control $(\rho=.41)$, observability $(\rho=.38)$, subjective norm $(\rho=.33)$, and trialability $(\rho=.32)$. None of the confidence intervals for the relationships noted above include zero. Except for complexity, all of the proposed antecedents were found to have a positive and significant correlation with adoption propensity (Weigel et al.; Weigel, Hazen, Cegielski, \& Hall, 2014). Al-Gahtani (2003) conducted research on computer adoption in Saudi Arabi. This researcher used Rogers' (2003) five PCIs to understand computer adoption and use. Al-Gahtani found that all five characteristics correlated significantly with computer use and adoption with complexity having a negative correlation. Chiasson and Lovato (2001) investigated factors impacting the adoption of software. These researchers found that initially, all five of Rogers' (1964) characteristics were important to adopters, but importance narrows down to a few factors as time progresses. Aligned with previous literature, the following hypotheses are proffered: H3e: The perceived relative advantage will have a positive effect on the adoption intention.

H3f: The perceived complexity will have a negative effect on the adoption intention. H3g: The perceived compatibility will have a positive effect on the adoption intention. 


\section{METHODOLOGY}

\section{Participants and Procedure}

\section{Research Design}

The unit of analysis for this study is at the individual level. The target population we are interested in is the residents in the U.S. who have considered adopting a new technology. We separated the participants into two groups randomly, with one group answering the survey for adopting an emerging technology, and the other group answering the survey for enabling technology. We collected at least 200 usable responses for each survey.

This study employs a survey method. Following appropriate informed and blind pilot studies and revisions, an exploratory study was conducted using an online survey in order to gain a better understanding of the social embeddedness and the perceived characteristics of an innovation as well as to validate the model.

The survey was separated into two versions: one for emerging technology, and one for enabling technology. In this study, emerging technology is defined as a radically novel and relatively fast-growing technology with the potential to exert a considerable influence on society. Most of its influence lies in the future and so it is still somewhat uncertain and ambiguous. For example, Dyson is a product innovator that follows a radical, emerging technology approach to its product offerings. Dyson has gone through the process of reinventing often overlooked categories of domestic appliances such as the vacuum and fan. They have delivered market innovation and influence through their technology. Other examples of emerging technologies include the Apple watch, Amazon 
dash button, Augmented Reality (AR), 3D printing, self-driving cars and drones, vertical farming, and solar photovoltaic for personal use etc.

The enabling technology is defined as either relatively simple extensions or modifications to existing products or technologies that result in a new way to do old things or may provide a vehicle for new opportunities. Enabling technologies can often be realized by combining existing technologies to create something entirely new. For example, combining the Internet and a simple computer with a common gasoline pump to create a smart pump, other examples of enabling technology include Google Nest Thermostat (controlling the temperature through mobile app), cameras with direct editing abilities via onboard computers, Smart Home Security Systems in which home surveillance cameras are connected to the internet to automate the security of your home.

The survey instrument was constructed and delivered online via Qualtrics and recruited at least 200 subjects for each version. The research model was tested and refined using data collected for the two different types of technologies. Then the results for these two types of technologies were analyzed and compared.

\section{Measurements}

We used a 7-point Likert scale in order to measure the questionnaire items with 1 indicating 'Low degree/Strongly disagree' and 7 indicating 'High degree/Strongly agree'. The final items used for constructs are listed in the survey in Appendix.

The constructs for perceived characteristics of innovations are mainly adapted from Moore and Benbasat (1991) as reflective constructs; the construct for Adoption Intention (AI) was 
developed and adapted from Carrus, Passafaro, and Bonnes (2008); Casaló, Flavián, and Guinalíu (2010); Kim, Yun, and Lee (2014); and the construct for Social Embeddedness was developed and adapted based on Reed and Selbee (2003) Kim et al. (2014); Kurz, Linden, and Sheehy (2007) and was developed as formative construct.

For the perceived characteristics of technology, modifications were made to Trialability and Observability. The two constructs were split into Trialability - before (T-before), Trialability - after (T-after), Observability - before (O-before), and Observability - after (O-after) basing on the product launch time. In other words, the degree the innovation can be experimented with or practiced before the product launch is categorized as T-before, while the degree the innovation can be experimented with or practiced after the product launch is categorized as T-after. The same is for Observability. The rest three perceived characteristics of technology had the similar definition as in Moore and Benbasat (1991). The Relative Advantage (RA) is the degree an innovation is perceived as a better idea; the Compatibility is the degree of perceived consistency with values, experiences, and needs of potential adopters; and the Ease of Use (EOU), or complexity is the degree of difficulty with using the innovation.

The social embeddedness was tapped into three dimensions, including social connectivity (links to one's social context) (Reed \& Selbee, 2003), social anchoring (values, beliefs, and life-ordering principles, especially when periodically affirmed with like-minded people) (Reed \& Selbee, 2003), and social continuity(Kim et al., 2014; Kurz et al., 2007; Reed \& Selbee, 2003). 


\section{DATA ANALYSIS AND RESULTS}

The psychometric properties of the measures were examined in terms of item loadings, internal consistency, and discriminant validity. The former two metrics are deemed acceptable if greater than 0.70 (Claes Fornell \& David F Larcker, 1981). To check if the results support the discriminant validity of the constructs, we checked whether: a) items load more strongly on particular constructs than on other ones; b) the square root of the average variance extracted (AVE) is larger than the inter-construct correlations (Chin, 1998).

We carried out an exploratory factor analysis to check the item loadings and confirmatory factor analysis to examine convergent and discriminant validity of the constructs. EFA were conducted using SPSS and we used it to determine the latent constructs necessary to account for the correlations among all the variables. The analysis informs us how the items load towards the constructs and whether there is no cross-loading. In EFA the items can load towards any constructs, while in CFA the measures can load only on previously defined constructs (based on subject matter knowledge). Thus, further on, confirmatory factor analysis using ADANCO (ADANCO, 2019) was be carried out. Beta coefficients and R-squared values of the path equations informed us of the loadings of the items towards particular constructs. This way we also examined for convergent validity - that items of a particular construct are correlated; and discriminant validity - that items of different constructs are not correlated. Inter-item correlation matrices were used to examine and present the convergent and discriminant validity. The fit indices indicating whether the measurement model is a good fit were reported. 
We used Partial Least Squares to test the hypothesized structural model. The justification for using PLS is two-fold: a) it allows us to study patterns of causation among the variables; and b) our model consists of multi-item constructs and PLS enables examination of such constructs. Furthermore, PLS enables the construction of formative models (as well as reflective relations), which are embedded in this study. In formative constructs, the items influence their corresponding composite variable. PLS is also a good solution for studies with relatively small sample sizes (Hsu, Chen, \& Hsieh, 2006). The general criterion is for the minimum sample size for PLS to be ten times greater than the maximum number of paths towards any variable in the model (Chin \& Newsted, 1999). In this case the planned sample size 200 for emerging technology and enabling technology should be sufficient as it well crosses the necessary threshold.

\section{Characteristics of the Survey Sample}

For the emerging technology survey, we received survey responses from 447 individuals. After eliminating 38 invalid responses, we retained 409 usable responses for data analysis. The effective response rate is $91.5 \%$.

For the enabling technology survey, we received responses from 212 individuals. After eliminating 6 invalid responses, we retained 206 usable responses for enabling technology. The effective response rate is $97.2 \%$. 


\section{Table 1. Characteristics of the Sample}

\begin{tabular}{|c|c|c|c|c|}
\hline & \multicolumn{2}{|c|}{ Emerging Technology } & \multicolumn{2}{|c|}{ Enabling technology } \\
\hline \multicolumn{5}{|l|}{ Gender } \\
\hline Female & 157 & $38.39 \%$ & 75 & $36.41 \%$ \\
\hline Male & 250 & $61.12 \%$ & 131 & $63.59 \%$ \\
\hline Unknown & 2 & $0.49 \%$ & - & - \\
\hline \multicolumn{5}{|l|}{ Age group } \\
\hline $18-25$ & 66 & $16.14 \%$ & 35 & $16.99 \%$ \\
\hline $26-40$ & 289 & $70.66 \%$ & 130 & $63.11 \%$ \\
\hline $41-59$ & 42 & $10.27 \%$ & 33 & $16.02 \%$ \\
\hline $60+$ & 12 & $2.93 \%$ & 7 & $3.40 \%$ \\
\hline Unknown & - & - & 1 & $0.49 \%$ \\
\hline \multicolumn{5}{|l|}{ Ethnicity } \\
\hline African American & 21 & $5.13 \%$ & 11 & $5.34 \%$ \\
\hline $\begin{array}{l}\text { American Indian or Alaska } \\
\text { Native }\end{array}$ & 16 & $3.91 \%$ & 5 & $2.43 \%$ \\
\hline Asian & 193 & $47.19 \%$ & 100 & $48.54 \%$ \\
\hline Caucasian & 162 & $39.61 \%$ & 81 & $39.32 \%$ \\
\hline Hispanic or Latino & 15 & $3.67 \%$ & 6 & $2.91 \%$ \\
\hline Middle Eastern & 1 & $0.24 \%$ & 1 & $0.49 \%$ \\
\hline $\begin{array}{l}\text { Native Hawaiian or Pacific } \\
\text { Islander }\end{array}$ & 1 & $0.24 \%$ & 0 & $0.00 \%$ \\
\hline Unknown & - & - & 2 & $0.97 \%$ \\
\hline \multicolumn{5}{|l|}{ Education } \\
\hline High School & 14 & $3.42 \%$ & 14 & $6.80 \%$ \\
\hline Some College & 31 & $7.58 \%$ & 27 & $13.11 \%$ \\
\hline Bachelor's Degree & 240 & $58.68 \%$ & 115 & $55.83 \%$ \\
\hline Some graduate school & 18 & $4.40 \%$ & 9 & $4.37 \%$ \\
\hline Master's Degree & 99 & $24.21 \%$ & 38 & $18.45 \%$ \\
\hline Doctoral Degree & 7 & $1.71 \%$ & 3 & $1.46 \%$ \\
\hline
\end{tabular}

As shown in Table 1, the sample represented a wide range of population with different age group, education and ethnicity. The proportion of female and male respondents is balanced, with the number of male respondents slightly higher than the number of female respondents. Most respondents come from the age group of 26 to 40, then followed by the age group of $18-25$, indicating that almost $80 \%$ of the respondents are young adults. 
As of ethnicity, Asian and Caucasian comprised of nearly $90 \%$ of the respondents. Of all the respondents, at least half of them had bachelor's degree, and around quarter of them had master's degree. The sample showed that the respondents are generally highly educated and come from young to middle aged group.

Non-response bias occurs when the respondents participated in the survey differ great from those who didn't (Fowler, 2009). To examine if non-response bias was a possible problem, we split the sample into two subgroups based on the response time, and then compared the two groups of data on demographic, social embeddedness and perceived characteristics of technology. No significant differences were found, hence non-response bias was determined not be an issue.

Common method bias (CMB) happens when variations in responses are caused by the constructs rather than the actual predispositions of the respondents that the constructs attempts to measure (Podsakoff, MacKenzie, Lee, \& Podsakoff, 2003). To assess if common method bias was an issue, we performed the Harman's one-factor test. If the total variance for a single factor is less than 50\%, then CMB should not be a serious problem. All items are loaded on one single factor, and the results showed that the total variance for a single factor is $36.8 \%$ for the emerging dataset, and $37.6 \%$ for the enabling dataset, indicating CMB does not affect the data and results (Podsakoff et al., 2003). 


\section{Measurement Validation}

We modeled the indicators of perceived characteristics of technology, social embeddedness and adoption intention. Our validation results suggest that all measures reached satisfactory construct validity and no significant multicollinearity. The detailed results are listed below.

The reliability indexes of latent constructs were evaluated by composite reliability. Composite reliability of 0.70 or higher is considered acceptable (Werts, Linn, \& Jöreskog, 1974). For adequate convergent and discriminant validity, the square root of the average variance extracted (AVE) should be at least 0.70 and exceed the correlations between the foal construct and other constructs (Gefen, Straub, \& Boudreau, 2000). Furthermore, standardized item loadings should be greater than 0.7 and items should load more highly on their intended construct than on other constructs (Gefen et al., 2000).

The details of the reliability indexes are shown in Table 2. Dijkstra-Henseler's rho $\left(\rho_{A}\right)$ estimates the reliability of reflective measurement models when PLS mode A was used. "Currently the $\rho A$ is the only consistent estimate of the reliability of construct scores obtained through PLS path modeling." Then composite reliability (also called DillonGoldstein's rho, factor reliability, J“oreskog's rho, McDonald's $\omega$ ) is an estimate of the reliability of sum scores pertaining to a reflective measurement model (Henseler, Ringle, \& Sinkovics, 2009). Cronbach's alpha $(\alpha)$ is a lower bound estimate for the reliability of a reflective measurement model (Henseler et al., 2009), and is considered as a measure of scale reliability. Cronbach's Alpha measures internal consistency, that is, how closely related a set of items are as a group. If the value of Cronbach's Alpha is greater than 0.7 , 
it is thought to be acceptable. As shown in Table 2, all reliability indexes for the seven perpetually measured reflective constructs (relative advantage, compatibility, ease of use, observability, trialability, adoption intention and social embeddedness) are much higher than 0.70 , suggesting acceptable reliability of the measures.

\begin{tabular}{|l|c|c|c|}
\hline \multicolumn{1}{|c|}{ Table 2. Construct Reliability } \\
\hline Construct & $\begin{array}{c}\text { Dijkstra-Henseler's rho } \\
\left(\rho_{\mathrm{A}}\right)\end{array}$ & $\begin{array}{c}\text { Jöreskog's rho } \\
\left(\rho_{\mathrm{c}}\right)\end{array}$ & $\begin{array}{c}\text { Cronbach's alpha } \\
(\alpha)\end{array}$ \\
\hline Observability-before & 0.877 & 0.913 & 0.872 \\
\hline Observability-after & 0.850 & 0.891 & 0.837 \\
\hline Trialability-before & 0.818 & 0.912 & 0.808 \\
\hline Trialability-after & 0.741 & 0.884 & 0.739 \\
\hline Relative advantage & 0.884 & 0.908 & 0.878 \\
\hline Compatibility & 0.805 & 0.868 & 0.799 \\
\hline Ease of use & 0.801 & 0.869 & 0.799 \\
\hline Adoption intention & 0.831 & 0.895 & 0.824 \\
\hline
\end{tabular}

The square roots of the variance extracted (AVE) are listed in Table 3. AVE is a number between 0 and 1 that assess the average indicator reliability. It is often used to assess whether the construct was unidimensional. Common cut-off point for a reflective construct to exhibit sufficient unidimensionality is above 0.5 (Claes Fornell \& David F. Larcker, 1981). As shown in Table 3, all constructs showed good unidimensionality. 


\section{Table 3. Convergent Validity}

\begin{tabular}{|l|c|}
\hline \multicolumn{1}{|c|}{ Construct } & Average Variance Extracted (AVE) \\
\hline Observability-before & 0.724 \\
\hline Observability-after & 0.671 \\
\hline Trialability-before & 0.839 \\
\hline Trialability-after & 0.793 \\
\hline Relative advantage & 0.623 \\
\hline Compatibility & 0.623 \\
\hline Ease of use & 0.624 \\
\hline Adoption intention & 0.739 \\
\hline
\end{tabular}

Discriminant validity assesses if the two conceptually different constructs are truly different statistically. Table 4 is showing discriminant validity results using the FornellLarcker criterion (Claes Fornell \& David F. Larcker, 1981). The criterion is often used to assess the degree of shared variance between the latent constructs. It postulates that a construct's AVE should be higher than its squared correlations with all other constructs in the model. As illustrated by Table 4, all constructs showed good discriminant validity.

\section{Table 4. Discriminant Validity for Reflective Constructs}

\begin{tabular}{|l|c|c|c|c|c|c|c|c|}
\hline Constructs & O-before & O-after & T-before & T-after & RA & C & EOU & AI \\
\hline O-before & 0.724 & & & & & & & \\
\hline O-after & 0.168 & 0.671 & & & & & & \\
\hline T-before & 0.468 & 0.105 & 0.839 & & & & & \\
\hline T-after & 0.145 & 0.443 & 0.139 & 0.793 & & & & \\
\hline RA & 0.256 & 0.324 & 0.177 & 0.264 & 0.623 & & & \\
\hline C & 0.204 & 0.280 & 0.090 & 0.302 & 0.568 & 0.623 & & \\
\hline EOU & 0.142 & 0.307 & 0.049 & 0.315 & 0.416 & 0.558 & 0.624 & \\
\hline AI & 0.211 & 0.243 & 0.086 & 0.275 & 0.546 & 0.522 & 0.391 & 0.739 \\
\hline
\end{tabular}

Notes: O-before: observability - before; O-after: observability - after; T-before: trialability - before; T-after: trialability -after; RA: relative advantage; C: compatibility; EOU: ease of use; AI: adoption intention. 
Table 5 contains the correlations between indicators and constructs. The cross-loadings are calculated using correlations of indicators to constructs. Bolded numbers are loadings to for indicators to its' own construct.

\begin{tabular}{|c|c|c|c|c|c|c|c|c|}
\hline or & $\begin{array}{c}\text { O- } \\
\text { before }\end{array}$ & $\begin{array}{c}\text { O- } \\
\text { after }\end{array}$ & $\begin{array}{c}\mathrm{T}- \\
\text { before }\end{array}$ & $\begin{array}{c}\text { T- } \\
\text { after }\end{array}$ & RA & C & EOU & AI \\
\hline Q4_1 & 0.801 & 0.285 & 0.505 & 0.264 & 0.402 & 0.404 & 0.300 & 0.385 \\
\hline Q4_2 & 0.888 & 0.375 & 0.564 & 0.348 & 0.449 & 0.408 & 0.344 & 0.411 \\
\hline Q4_3 & 0.857 & 0.337 & 0.604 & 0.343 & 0.429 & 0.358 & 0.306 & 0.397 \\
\hline Q4_4 & 0.855 & 0.392 & 0.652 & 0.335 & 0.439 & 0.367 & 0.329 & 0.372 \\
\hline Q4_5 & 0.311 & 0.776 & 0.286 & 0.481 & 0.420 & 0.345 & 0.365 & 0.306 \\
\hline Q4_6 & 0.414 & 0.866 & 0.383 & 0.554 & 0.511 & 0.453 & 0.477 & 0.450 \\
\hline Q4_7 & 0.275 & 0.800 & 0.190 & 0.573 & 0.483 & 0.474 & 0.495 & 0.438 \\
\hline Q4_8 & 0.329 & $\mathbf{0 . 8 3 2}$ & 0.183 & 0.572 & 0.445 & 0.454 & 0.473 & 0.407 \\
\hline Q5_1 & 0.630 & 0.312 & 0.905 & 0.320 & 0.377 & 0.258 & 0.192 & 0.263 \\
\hline Q5_2 & 0.624 & 0.283 & 0.927 & 0.361 & 0.394 & 0.289 & 0.213 & 0.273 \\
\hline Q5_3 & 0.394 & 0.583 & 0.367 & 0.884 & 0.453 & 0.472 & 0.465 & 0.444 \\
\hline Q5_4 & 0.287 & 0.602 & 0.299 & 0.897 & 0.462 & 0.506 & 0.532 & 0.490 \\
\hline Q6_1 & 0.401 & 0.419 & 0.405 & 0.394 & 0.793 & 0.575 & 0.488 & 0.546 \\
\hline Q6_2 & 0.430 & 0.460 & 0.367 & 0.405 & 0.795 & 0.609 & 0.516 & 0.576 \\
\hline Q6_3 & 0.423 & 0.437 & 0.355 & 0.388 & 0.789 & 0.562 & 0.489 & 0.555 \\
\hline Q6_4 & 0.323 & 0.412 & 0.277 & 0.373 & 0.689 & 0.512 & 0.419 & 0.524 \\
\hline Q6_5 & 0.360 & 0.467 & 0.222 & 0.424 & 0.811 & 0.668 & 0.575 & 0.661 \\
\hline Q6_6 & 0.455 & 0.495 & 0.379 & 0.444 & 0.848 & 0.626 & 0.549 & 0.622 \\
\hline Q7_1 & 0.370 & 0.413 & 0.238 & 0.385 & 0.628 & 0.798 & 0.573 & 0.613 \\
\hline Q7_2 & 0.445 & 0.442 & 0.279 & 0.467 & 0.694 & 0.830 & 0.616 & 0.652 \\
\hline Q7_3 & 0.298 & 0.439 & 0.181 & 0.446 & 0.545 & 0.777 & 0.611 & 0.524 \\
\hline Q7_4 & 0.294 & 0.374 & 0.243 & 0.441 & 0.492 & 0.751 & 0.560 & 0.473 \\
\hline Q8_1 & 0.277 & 0.377 & 0.171 & 0.422 & 0.479 & 0.589 & 0.756 & 0.470 \\
\hline Q8_2 & 0.321 & 0.464 & 0.177 & 0.447 & 0.536 & 0.611 & 0.801 & 0.516 \\
\hline Q8_3 & 0.319 & 0.472 & 0.189 & 0.463 & 0.510 & 0.600 & 0.785 & 0.505 \\
\hline Q8_4 & 0.274 & 0.437 & 0.165 & 0.441 & 0.512 & 0.563 & 0.816 & 0.485 \\
\hline Q9_1 & 0.420 & 0.378 & 0.283 & 0.372 & 0.628 & 0.576 & 0.469 & $\mathbf{0 . 8 3 8}$ \\
\hline Q9_2 & 0.368 & 0.409 & 0.199 & 0.447 & 0.572 & 0.606 & 0.565 & 0.842 \\
\hline Q9_3 & 0.400 & 0.479 & 0.273 & 0.524 & 0.702 & 0.676 & 0.576 & 0.898 \\
\hline
\end{tabular}


The results suggest that all items load higher on their intended construct than other constructs (Notes: O-before indicates observability - before; O-after indicates observability - after; T-before indicates trialability - before; T-after indicates trialability after; RA indicates relative advantage; $\mathrm{C}$ indicates compatibility; EOU indicates ease of use; AI indicates adoption intention).

Table 6 shows the result for variance inflation factor (VIF) statistics for construct social embeddedness. Since social embeddedness is a formative construct, a high reliability score could lead to excessive multicollinearity problems and hence make the model less stable. In general, if the VIF statistic is less than 3.3, we could keep the indicator and assume that multicollinearity is not significant problem (Diamantopoulos \& Siguaw, 2006). As shown in Table 6, all VIF statistics for social embeddedness are lower than 3.3, so multicollinearity should not be a problem.

\begin{tabular}{|l|c|}
\hline \multicolumn{2}{|c|}{ Table 6. VIF Statistics for Formative Indicators } \\
\hline Indicator & Social Embeddedness \\
\hline Q10_1 & 1.726 \\
\hline Q10_2 & 1.768 \\
\hline Q10_4 & 1.464 \\
\hline Q10_6 & 1.526 \\
\hline
\end{tabular}

Test of the Structural Model - Emerging Technology

The final sample size for the analysis of the proposed structural model for emerging technology was 409 after excluding 38 responses with extreme values. We conducted ttests to compare these 409 responses with the 38 responses on variables of demographic, social embeddedness and perceived characteristics of technology. No significant 
differences were found between the two groups on these variables. Missing values are imputed using the hot deck method. The hot deck method replaces the missing values with an observed response from a "similar" unit. Compared to mean imputation method, the hot deck method only generates plausible values. In addition, compared to listwise deletion, hot deck imputation provides more efficiency, since information in the incomplete cases is kept for analysis as well (Andridge \& Little, 2010).

Our Structural equation modelling results are shown in Figure 6.

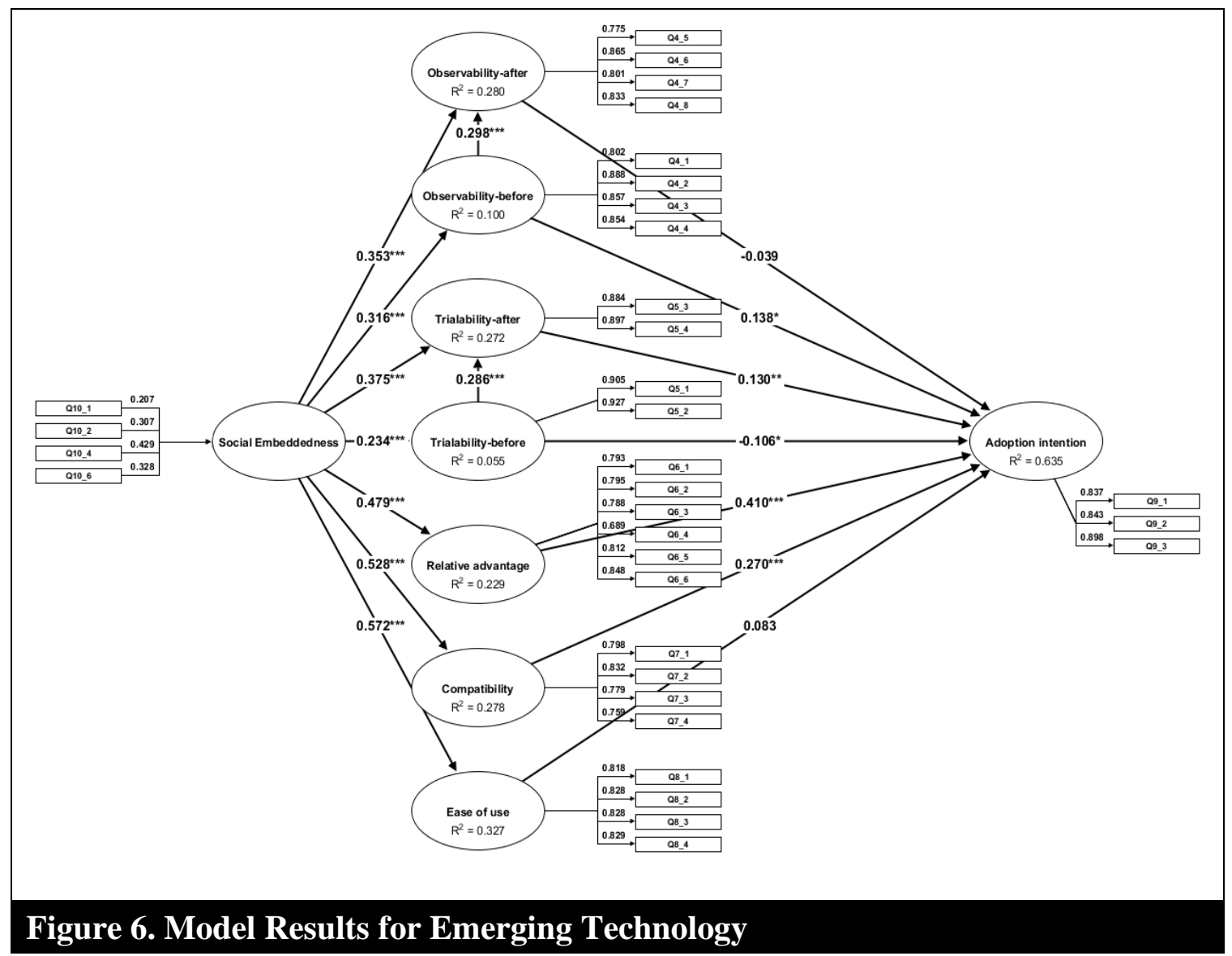

As indicated by Figure 6, social embeddedness has significant effect on all the perceived characteristics of technology. However, under the influence of social embeddedness, two 
previously considered important perceived characteristics (ease of use and observability after) are no longer considered important when it comes to adoption intention for emerging technology.

Table 7 shows the coefficient of determination and adjusted R-squared values for emerging technology. The coefficient of determination shows how much of the variance in the endogenous variable is explained by the independent variables. The adjusted Rsquared is a modification for the coefficient of determination for the sample size and addition of independent variables. Only observability and trialability before product launch had relatively low but still acceptable R-squared values.

\section{Table 7. R-Squared - Emerging Technology}

\begin{tabular}{|l|c|c|}
\hline Construct & Coefficient of determination $\left(\mathrm{R}^{2}\right)$ & Adjusted $\mathrm{R}^{2}$ \\
\hline Observability-before & 0.1001 & 0.0979 \\
\hline Observability-after & 0.2796 & 0.2760 \\
\hline Trialability-before & 0.0546 & 0.0522 \\
\hline Trialability-after & 0.2720 & 0.2684 \\
\hline Relative advantage & 0.2292 & 0.2273 \\
\hline Compatibility & 0.2784 & 0.2766 \\
\hline Ease of use & 0.3269 & 0.3253 \\
\hline Adoption intention & 0.6354 & 0.6290 \\
\hline
\end{tabular}

Table 8 shows the effect size using Cohen's $\mathrm{f}^{2}$. The effect size indicates how substantial a direct effect is, usually a Cohen's $\mathrm{f}^{2}$ value greater than 0.35 is considered to have a strong effect; a Cohen's $\mathrm{f}^{2}$ value between 0.15 to 0.35 is considered to have moderate effect; a Cohen's $f^{2}$ value between 0.02 to 0.15 is considered to be weak; and less than 0.02 is considered to be unsubstantial. Except for observability-after, all effects had substantial 
effect. The bolded numbers are the effects that are moderate and strong. For emerging technology, the social embeddedness had only weak effect on observability and trialability before the product launch; however, it had moderate effect on observability and trialability after the product launch. Social embeddedness had generally strong effects on other three perceived characteristics of technology, but only relative advantage had moderate effect on adoption intention.

\section{Table 8. Effect Overview - Emerging Technology}

\begin{tabular}{|l|c|c|c|c|}
\hline \multicolumn{1}{|c|}{ Effect } & Beta & $\begin{array}{c}\text { Indirect } \\
\text { effects }\end{array}$ & $\begin{array}{c}\text { Total } \\
\text { effect }\end{array}$ & $\begin{array}{c}\text { Cohen's } \\
\mathrm{f}^{2}\end{array}$ \\
\hline Social Embeddedness -> Observability-before & 0.316 & & 0.316 & 0.111 \\
\hline Social Embeddedness -> Observability-after & 0.353 & 0.094 & 0.447 & $\mathbf{0 . 1 5 5}$ \\
\hline Social Embeddedness -> Trialability-before & 0.234 & & 0.234 & 0.058 \\
\hline Social Embeddedness -> Trialability-after & 0.375 & 0.067 & 0.441 & $\mathbf{0 . 1 8 2}$ \\
\hline Social Embeddedness -> Relative advantage & 0.479 & & 0.479 & $\mathbf{0 . 2 9 7}$ \\
\hline Social Embeddedness -> Compatibility & 0.528 & & 0.528 & $\mathbf{0 . 3 8 6}$ \\
\hline Social Embeddedness -> Ease of use & 0.572 & & 0.572 & $\mathbf{0 . 4 8 6}$ \\
\hline Observability-before -> Observability-after & 0.298 & & 0.298 & 0.111 \\
\hline Trialability-before -> Trialability-after & 0.286 & & 0.286 & 0.106 \\
\hline Observability-before -> Adoption intention & 0.138 & -0.012 & 0.126 & 0.023 \\
\hline Observability-after -> Adoption intention & -0.039 & & -0.039 & 0.002 \\
\hline Trialability-before -> Adoption intention & -0.106 & 0.037 & -0.069 & 0.015 \\
\hline Trialability-after -> Adoption intention & 0.130 & & 0.130 & 0.021 \\
\hline Relative advantage -> Adoption intention & 0.410 & & 0.410 & $\mathbf{0 . 1 6 1}$ \\
\hline Compatibility -> Adoption intention & 0.270 & & 0.270 & 0.054 \\
\hline Ease of use -> Adoption intention & 0.083 & & 0.083 & 0.006 \\
\hline Social Embeddedness -> Adoption intention & & 0.445 & 0.445 & \\
\hline
\end{tabular}


Table 9 shows the results of the hypotheses testing for the emerging technology. we use the p-value of the parameters in the research model to determine the order of estimating the influence of the perceived characteristics of innovation and social embeddedness.

Table 9. Summary of Hypotheses - Emerging Technology
\begin{tabular}{|l|l|c|c|c|}
\hline Hypotheses & t-value & p-value & Supported \\
\hline H1a & Social Embeddedness -> Observability-before & 5.431 & 0.000 & $\checkmark$ \\
\hline H1b & Social Embeddedness -> Observability-after & 7.449 & 0.000 & $\checkmark$ \\
\hline H1c & Social Embeddedness -> Trialability -before & 4.432 & 0.000 & $\checkmark$ \\
\hline H1d & Social Embeddedness -> Trialability -after & 8.175 & 0.000 & $\checkmark$ \\
\hline H1e & Social Embeddedness -> Relative advantage & 7.809 & 0.000 & $\checkmark$ \\
\hline H1f & Social Embeddedness -> Compatibility & 9.274 & 0.000 & $\checkmark$ \\
\hline H1g & Social Embeddedness -> Ease of use & 10.541 & 0.000 & $\checkmark$ \\
\hline H2a & Observability-before -> Observability-after & 4.672 & 0.000 & $\checkmark$ \\
\hline H2b & Trialability -before -> Trialability -after & 5.076 & 0.000 & $\checkmark$ \\
\hline H3a & Observability-before -> Adoption intention & 2.108 & 0.035 & $\checkmark$ \\
\hline H3b & Observability-after -> Adoption intention & -0.703 & 0.483 & - \\
\hline H3c & Trialability-before -> Adoption intention & -1.398 & 0.162 & - \\
\hline H3d & Trialability -after -> Adoption intention & 2.754 & 0.006 & $\checkmark$ \\
\hline H3e & Relative advantage -> Adoption intention & 5.728 & 0.000 & $\checkmark$ \\
\hline H3f & Compatibility -> Adoption intention & 4.147 & 0.000 & $\checkmark$ \\
\hline H3g & Ease of use -> Adoption intention & 1.354 & 0.176 & - \\
\hline
\end{tabular}

Relationship Between Social Embeddedness and the Perceived Characteristics of Technology

Of the 7 hypotheses regarding relationship between social embeddedness and the perceived characteristics of technology, all of them are supported. The result suggests that the degree how a person is socially connected, how his values, beliefs and lifeordering principles are periodically affirmed with like-minded people, and the level of 
social continuity affects how one perceive the technology. The more one is socially embedded, the more one can perceive the observability of a technology, both before (coefficient: 0.316, standard error: 0.058 p-value: 0.000 ) and after (coefficient: 0.298, standard error: $0.064 \mathrm{p}$-value: 0.000 ) the product launch. It would be obvious to see the conclusions that the more one connects with his social surroundings, the more information he would get, the more likely one would hear the information related to the technology from his social relations, thus increasing the chance of seeing the technology, or the perceived observability of the technology. The effect from social embeddedness to observability should persist from before to after the product launch, and the hypotheses test results backed it up. The coefficient for observability - after is slightly larger than observability - before. The results are reasonable, since one would expect to see more of a product after the product launch.

The relationship between social embeddedness and trialability assimilates the relationship between social embeddedness and observability. The more one is socially embedded, the more one would perceive the trialability of the technology, both before (coefficient: 0.234, standard error: 0.053 p-value: 0.000 ) and after (coefficient: 0.441, standard error: 0.054 p-value: 0.000 ) the product launch.

The relationships between social embeddedness and the rest of the three perceived characteristics of technology: relative advantage (coefficient: 0.479 , standard error: 0.061 p-value: 0.000 ), compatibility (coefficient: 0.528 , standard error: 0.057 p-value: 0.000 ), and ease of use (coefficient: 0.572, standard error: 0.054 p-value: 0.000 ) are significant. 
The Effect of Before and After Product Launch

The results suggest that the perceived pre-product launch observability would have a significant and positive effect on post-product launch observability (coefficient: 0.298 , standard error: $0.064 \mathrm{p}$-value: 0.000$)$. The same is for pre-product launch trialability and post-launch trialability (coefficient: 0.286 , standard error: 0.056 p-value: 0.000 ). That is to say, the more one sees and tries the product before its launch (wither through videos, reviews, or test models, beta versions etc.), the more likely one can see and try the product after launch. It can be explained using the Baader-Meinhof phenomenon (Kershner, 2015). The Baader-Meinhof phenomenon is also known as known as frequency illusion or recency illusion. It happens when you hear something and suddenly you found that everyone else around you is talking about it, and you are surrounded by it constantly (Zwicky, 2005). The truth is you are seeing it more, but you are also noticing it more. The phenomenon explains why the perceived product observability and trialability before product launch would influence perceived product observability and trialability after the product launch. Because one will notice the product more often once he or she saw the product.

\section{Relationship Between the Perceived Characteristics of Technology and Adoption} Intention

Of the 7 hypotheses regarding adoption intention, $\mathrm{H} 3 \mathrm{~b}, \mathrm{H} 3 \mathrm{c}$, and $\mathrm{H} 3 \mathrm{~g}$ did not find enough evidence of support. The rest four hypotheses were supported. The observability - before had significant and positive effect on adoption intention (coefficient: 0.126 , standard error: $0.060 \mathrm{p}$-value: 0.035 ). While compared with the relationship between 
observability -after and adoption intention, the effect was not significant (coefficient: 0.039 , standard error: $0.055 \mathrm{p}$-value: 0.482 ). This is an interesting finding and suggest that when a company is trying to launch a new product that is emerging technology, the more it shows up to the public, the more likely people would want to adopt it. However, the appearance of the technology does not affect people's adoption intention anymore once after the product launch. This can be viewed as a support for the disillusionment phase of Gartner's Hype Cycle shown in Figure 1. People had high hopes for the product before the product launch, thus had high level of adoption intention, but once the products come out to the public, people went into the trough of disillusionment and the degree of how often people can see the product after the launch does not affect the adoption intention anymore.

Opposite from observability, the pre-product launch trialability (coefficient: -0.069 , standard error: 0.050 p-value: 0.162 ) did not have significant effect on adoption intention. But the post-product-launch trialability (coefficient: 0.130 , standard error: $0.047 \mathrm{p}$-value: 0.006) had significant effects on adoption intention. One possible explanation is that if one can try out the product before the product launch, it would incur the trough of disillusionment early. More than often, one can only try out test models, beta versions etc. before a product launch. And beta versions and test models are often not as perfect as the final product since the reason for beta versions is to get customer feedback and improve the product. With this assumption, it would not be hard to understand why postlaunch trialability have significant effect on adoption intention. The more one can try out the product after the product launch, the more likely one can adjust previous experience with the product, and thus more likely to adopt the product. 
In line with previous literature, relative advantage (coefficient: 0.410, standard error: 0.072 p-value: 0.000 ), and compatibility (coefficient: 0.270 , standard error: 0.065 pvalue: 0.000 ) had positive and significant effect on adoption intention. But ease of use (coefficient: 0.083 , standard error: $0.061 \mathrm{p}$-value: 0.176 ) did not have significant effect on adoption intention. It could be the nature of emerging technology, since it's new and emerging, people may consider coolness and other effects more over if the product was easy to use or not. 
Test of the Structural Model - Enabling Technology

The final sample size for enabling technology survey is 206, 6 extreme cases were removed. We conducted same data process procedures as the one for emerging technology. We performed t-tests to compare these 206 responses with the 6 responses on all variables. No significant differences were found between the two groups on these variables. Missing values are imputed using the hot deck method. The results are shown below in Figure 7.

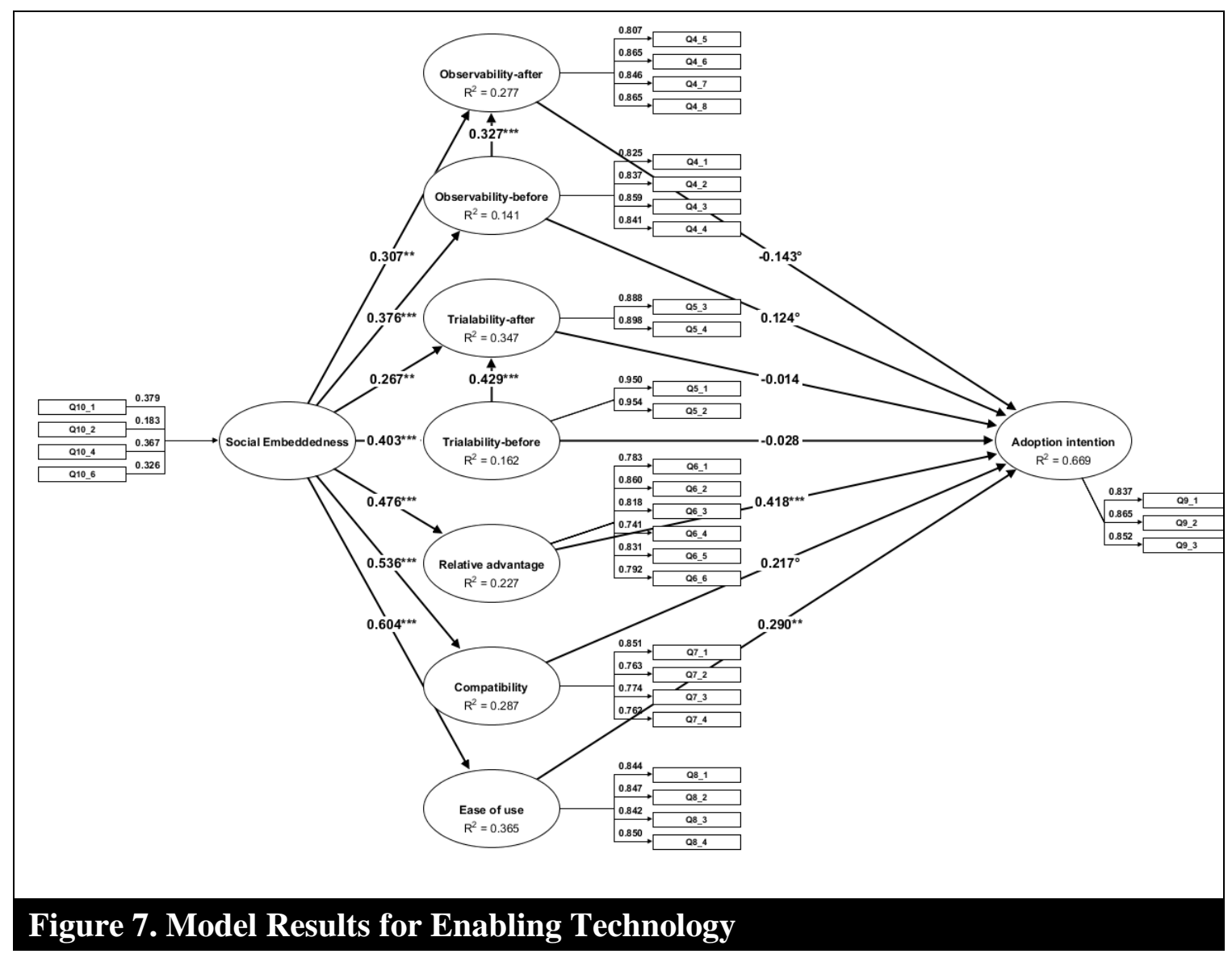

The social embeddedness is strongly associated with the all perceived characteristics for enabling technology, however, social embeddedness had less but still significant effect on 
trialability - after. Interestingly, ease of use became significant, whereas compared to emerging technology, ease of use was not significant. In addition, previous significant compatibility became borderline significant. Trialability in general did not have any significant effect. But observability in general was borderline significant.

Table 10 shows the coefficient of determination and adjusted R-squared values for enabling technology. Compared with emerging technology, all constructs had high Rsquared values.

\begin{tabular}{|l|c|c|}
\hline Table 10. R-Squared - Enabling Technology \\
\hline Construct & Coefficient of determination $\left(\mathrm{R}^{2}\right)$ & Adjusted $\mathrm{R}^{2}$ \\
\hline Observability-before & 0.1415 & 0.1373 \\
\hline Observability-after & 0.2766 & 0.2694 \\
\hline Trialability-before & 0.1623 & 0.1582 \\
\hline Trialability-after & 0.3474 & 0.3409 \\
\hline Relative advantage & 0.2265 & 0.2227 \\
\hline Compatibility & 0.2872 & 0.2837 \\
\hline Ease of use & 0.3645 & 0.3614 \\
\hline Adoption intention & 0.6694 & 0.6577 \\
\hline
\end{tabular}

Table 11 shows the effect size using Cohen's $\mathrm{f}^{2}$. Except for trialability before and trialability after to adoption intention, all effects are substantial. The bolded numbers are the effects that are moderate and strong. For enabling technology, the social embeddedness had moderate effect on observability and trialability before the product launch; however, it had weak effect on observability and trialability after the product launch, which is different from emerging technology. Similar to emerging technology, 
social embeddedness had generally strong effects on other three perceived characteristics of technology, but only relative advantage had moderate effect on adoption intention.

\begin{tabular}{|l|c|c|c|c|}
\hline \multicolumn{1}{|c|}{ Effect } & Beta & $\begin{array}{c}\text { Indirect } \\
\text { effects }\end{array}$ & $\begin{array}{c}\text { Total } \\
\text { effect }\end{array}$ & $\begin{array}{c}\text { Cohen's } \\
\mathrm{f}^{2}\end{array}$ \\
\hline Social Embeddedness -> Observability-before & 0.376 & & 0.376 & $\mathbf{0 . 1 6 5}$ \\
\hline Social Embeddedness -> Observability-after & 0.307 & 0.123 & 0.430 & 0.112 \\
\hline Social Embeddedness -> Trialability-before & 0.403 & & 0.403 & $\mathbf{0 . 1 9 4}$ \\
\hline Social Embeddedness -> Trialability-after & 0.267 & 0.173 & 0.440 & 0.091 \\
\hline Social Embeddedness -> Relative advantage & 0.476 & & 0.476 & $\mathbf{0 . 2 9 3}$ \\
\hline Social Embeddedness -> Compatibility & 0.536 & & 0.536 & $\mathbf{0 . 4 0 3}$ \\
\hline Social Embeddedness -> Ease of use & 0.604 & & 0.604 & $\mathbf{0 . 5 7 4}$ \\
\hline Observability-before -> Observability-after & 0.327 & & 0.327 & 0.127 \\
\hline Trialability-before -> Trialability-after & 0.429 & & 0.429 & $\mathbf{0 . 2 3 6}$ \\
\hline Observability-before -> Adoption intention & 0.124 & -0.047 & 0.077 & 0.017 \\
\hline Observability-after -> Adoption intention & -0.143 & & -0.143 & 0.028 \\
\hline Trialability-before -> Adoption intention & -0.028 & -0.006 & -0.034 & 0.001 \\
\hline Trialability-after -> Adoption intention & -0.014 & & -0.014 & 0.000 \\
\hline Relative advantage -> Adoption intention & 0.418 & & 0.418 & $\mathbf{0 . 1 7 1}$ \\
\hline Compatibility -> Adoption intention & 0.217 & & 0.217 & 0.034 \\
\hline Ease of use -> Adoption intention & 0.290 & & 0.290 & 0.081 \\
\hline Social Embeddedness -> Adoption intention & & 0.458 & 0.458 & \\
\hline
\end{tabular}

Table 12 provided the summary of the hypothesis testing results, $p$-value was used to determine the influence of the perceived characteristics of innovation and social embeddedness. Relative advantage has been consistently showing significant effect. However, the rest of the perceived characteristics of technology showed some interesting results. 


\section{Table 12. Summary of Hypothesis - Enabling Technology}

\begin{tabular}{|l|l|c|c|c|}
\hline \multicolumn{2}{|l|}{ Hypothesis } & t-value & p-value & Supported \\
\hline H1a & Social Embeddedness -> Observability-before & 5.893 & 0.000 & $\checkmark$ \\
\hline H1b & Social Embeddedness -> Observability-after & 5.133 & 0.000 & $\checkmark$ \\
\hline H1c & Social Embeddedness -> Trialability-before & 5.712 & 0.000 & $\checkmark$ \\
\hline H1d & Social Embeddedness -> Trialability-after & 5.882 & 0.000 & $\checkmark$ \\
\hline H1e & Social Embeddedness -> Relative advantage & 5.585 & 0.000 & $\checkmark$ \\
\hline H1f & Social Embeddedness -> Compatibility & 7.119 & 0.000 & $\checkmark$ \\
\hline H1g & Social Embeddedness -> Ease of use & 8.525 & 0.000 & $\checkmark$ \\
\hline H2a & Observability-before -> Observability-after & 3.574 & 0.000 & $\checkmark$ \\
\hline H2b & Trialability-before -> Trialability-after & 6.210 & 0.000 & $\checkmark$ \\
\hline H3a & Observability-before -> Adoption intention & 1.101 & 0.271 & - \\
\hline H3b & Observability-after -> Adoption intention & -1.882 & 0.060 & - \\
\hline H3c & Trialability-before -> Adoption intention & -0.560 & 0.576 & - \\
\hline H3d & Trialability-after -> Adoption intention & -0.156 & 0.876 & - \\
\hline H3e & Relative advantage -> Adoption intention & 4.885 & 0.000 & $\checkmark$ \\
\hline H3f & Compatibility -> Adoption intention & 1.927 & 0.054 & - \\
\hline H3g & Ease of use -> Adoption intention & 2.687 & 0.007 & $\checkmark$ \\
\hline
\end{tabular}

\section{Relationship Between Social Embeddedness and the Perceived Characteristics of}

\section{Technology}

Among the 7 hypotheses for social embeddedness and perceived characteristics of technology, all of them are supported. The results did not differ whether it's an emerging technology or enabling technology. However, there is an interesting finding regarding the coefficients for observability and trialability. Previously, for emerging technology, the coefficients for observability and trialability before product launch were lower than that of after product launch. Now, for enabling technology, the coefficient for observability 
before product launch (coefficient: 0.376 , standard error: 0.064 , p-value: 0.000 ) was higher than observability after product launch (coefficient: 0.307 , standard error: 0.084 , p-value: 0.000 ); and the coefficient for trialability before product launch (coefficient: 0.403, standard error: 0.071 , p-value: 0.000 ) was lower than the trialability before product launch (coefficient: 0.267, standard error: 0.075 , p-value: 0.000 ). This suggests that for enabling technology, how one is socially embedded is affects one's perceived observability and trialability more before the product launch, while for emerging technology, how one is socially embedded affects one's perceived observability and trialability more after the product launch. One possible explanation is that people are already familiar with enabling technology and enabling technology would be considered as less fancy than the emerging technology, therefore, there is less eager to see and try out the technology before the product launch. However, for emerging technology, people would be intrigued by it and wanting to see it and try it out before it's launch because people have never seen it before.

Similar with emerging technology, social embeddedness had positive and significant effect on the rest three perceived characteristics of technology: relative advantage (coefficient: 0.476 , standard error: 0.085 , p-value: 0.000 ), compatibility (coefficient: 0.536, standard error: 0.075 , p-value: 0.000 ), and ease of use (coefficient: 0.604 , standard error: 0.071, p-value: 0.000).

\section{The Effect of Before and After Product Launch}

Same with emerging technology, the perceived observability before product launch had positive and significant effect on the perceived observability after product launch 
(coefficient: 0.327, standard error: 0.092, p-value: 0.000); the perceived trialability before product launch had positive and significant effect on the perceived trialability after product launch (coefficient: 0.429, standard error: 0.069, p-value: 0.000).

Relationship Between the Perceived Characteristics of Technology and Adoption Intention

For enabling technology, only $\mathrm{H} 3 \mathrm{e}$, and $\mathrm{H} 3 \mathrm{~g}$ was supported. Observability before the product launch(coefficient: 0.124 , standard error: 0.070, p-value: 0.271 ), and observability after the product launch (coefficient: -0.143 , standard error: 0.076 , p-value: 0.060) had borderline effect on adoption intention; trialability before the product launch (coefficient: -0.028, standard error: 0.061, p-value: 0.576 ) and trialability after the product launch (coefficient: -0.014 , standard error: 0.091 , p-value: 0.876 ) had no significant effect on adoption intention. Compared with emerging technology, people tend to be more familiar with enabling technology, thus they care less about how much they can see or test the technology.

Relative advantage (coefficient: 0.418 , standard error: 0.086 , p-value: 0.000 ) has been showing consistently significant effect to adoption intention; but compatibility (coefficient: 0.217, standard error: 0.113, p-value: 0.054) showed only borderline significance for adoption intention; and interestingly, ease of use for emerging technology was not significant, however, ease of use (coefficient: 0.290, standard error: 0.108, p-value: 0.007 ) is now significant for adoption intention for enabling technology. Compared with emerging technology, people tend to consider ease of use as more important when it comes to adoption decision for enabling technology. It is logical since 
people use enabling technology more for regular daily life usage, it is important to be easy to use. On the other hand, the purpose to try out an emerging technology main due to its coolness or newness and would consider less of how easy it is to use. 


\section{DISCUSSIONS AND LIMITATIONS}

\section{Discussion}

We conducted this study to examine the relationship between social embeddedness, perceived characteristics of innovation and adoption intention. This study supports the characterization that social embeddedness influences the adoption intention through the perceived characteristics of innovation. With large sample sizes it was found that with the effect of social embeddedness, previously considered important perceived characteristics of innovation to adoption intention may no longer play similar role as before.

\section{Re-Assessed Weights for Each Perceived Characteristics of Innovation}

It is not surprising to see that relative advantage still plays an important role in adoption intention regardless of the type of technology and the level of social embeddedness. However, for emerging technology, with the effect of social embeddedness, the ease of use is becoming less important. Due to the nature of emerging technology, it is assumed that people tend to adopt an emerging technology more because of its newness or uniqueness and care less about if the technology is easy to use or not. And the fact that observability after launch did not matter to adoption intention backs up the trough of disillusionment phase of the Gartner's Hype Cycle. In the disillusion phase, people tend to lose faith and lower the inflated expectation of the technology even though the underlying technology may be growing exponentially. At this time, increased observability would not affect adoption intention unless there is a newer version/model of the technology comes out and brings up people's attention again. However, different from observability, trialability has had significant effects on adoption intention no matter 
before or after the product launch. But, trialability before product launch had a negative effect on adoption intention, it could be true, because there is usually a testing phase (or beta version) before the final product launches market. And these testing phase (or beta version) is likely to generate negative impression if there are a lot need to be modified before the final product launch. This could easily happen to emerging technology as it is still very new in every aspect. Nevertheless, the level that people can try out the technology after the product launch is important for adoption intention as it could be a chance for consumers to adjust their expectations and evaluations of the product. Similar with previous literature, compatibility remained as important aspect towards adoption intention.

For enabling technology, the observability and trialability became less important to adoption intention. But the ease of use was significant, compared to emerging technology. This implies that for a technology that people are already familiar with, it is more important to them that if the product is easy to use or not. And since that people understands the technology, it is less important if they can try or observe it. Interestingly, compatibility was only borderline significant to adoption intention. It seems that if the product is easy to use, and is relatively advantageous, they care less about if it is compatible with their current situation. For example, it happens when a previously Apple IOS system consumer decides to change one's phone to an Android phone (e.g. the Google Pixel) due to its innovativeness of camera processing technology etc. In this sense, people are breaking out one's old eco-system of technology by compromising compatibility and gradually develop into a new eco- system of technology. If changing an iPhone to a Google Pixel can be considered as breaking the old-eco-system, then 
changing one's phone plans to Google Fi can be thought as a step towards generating a new eco-system of technology, as only android phones has the ability to switch between networks smoothly. While switching network intelligently was the fundamental concept and selling point for Google Fi.

The reliability and validity of the social embeddedness and perceived characteristics of innovation are established in a number of ways. First, they were established through extensive literature review. Then they were tested using exploratory and confirmatory factor analyses. In addition, theses constructs were demonstrated to replicated across two independent samples, and each construct was demonstrated to be unidimensional and internally consistent. Thus, we are confident that these measures are capable of reliably describing the social embeddedness and perceived characteristics of the innovation.

The criterion-related validity of these measures was also assessed through testing a set of hypotheses derived from the current literature on innovation diffusion theory. As predicted, social embeddedness had strong, positive effects on all perceived characteristics. Expect for relative advantage, which has been consistently significant, the rest of the perceived characteristics played different roles towards adoption intention. It is reasonable to assume that with a deep social embedded innovation, consumers tend to ignore the ease of use of a product if it is considered as emerging technology; while people tend to ignore the trialability if it is considered as an enabling technology. It could due to the result of comparison effect and the nature of the technology, such that seeing people in my social network using this product makes me wanted to use this product. Or it could be an effect of trust, such that I wanted to adopt this technology because my 
friends had used this piece of technology and gave complement to the technology. Future research is needed to further uncover the mechanisms of the adoption of an innovation.

\section{Addition of Time Element in Traditional Innovation of Diffusion Models}

Different from previous study, we introduced the time element in the traditional model for innovation diffusion. Although Rogers (2003) suggested that there are four main elements in the diffusion of innovation theory including: 1) innovation, 2)

communication channels, 3) time, and 4) social system, the time aspect is ignored in most behavioral research (Rogers, 2003). There are few studies that considered the time effect, mostly in mathematical studies or conceptual papers. Pae and Lehmann (2003) studied the effect of intergeneration time on innovation diffusion rate for multi-generation products (Pae, J. H., \& Lehmann, D. R., 2003), and demonstrated that the more time elapse for the adjacent generation of product, the slower the adoption of the subsequent technology. But the main purpose for the study was to study the diffusion pattern for multigeneration technologies. As suggested by Lal and Kaicker (1988), earlier models of innovation diffusion have generally assumed immediate acceptance of a new innovation without considering the time lag between one knows the product and one adopts the product. So, they proposed an analytical model with distributed time lag. However, the focus of time element for their theoretical framework was between the knowledge of an innovation and its actual adoption. Minakov, Minakova, Galstyan, and Shiyanova (2015) proposed similar approach but added time as a constant in their analytical models.

To our knowledge, this study is the first study to examine the time effect of perceived characteristics of innovation, specifically for observability and trialability. The study 
added the time elements to the process of innovation diffusion, which was under discussed in behavioral research. And found that the observability and trialability before and after product launch had different impact on the adoption intention. The finding is important to innovation diffusion theory as it refined the models by integrating the time and social systems into the model and tested using empirical data, suggesting there should be new interpretations towards the theory. Practically, the study points ways for the tech-companies to market their products better by taking advantage of the social embeddedness and important time points in launching the new product.

\section{Different Type of Technology as Context Rather than Construct}

This study employed the survey method, and recruited two independent random sample for different type of technologies, i.e. emerging technology and enabling technology. Many studies have taken the innovativeness as a new construct, for example, Goldsmith and Foxall (2003) suggest that innovativeness is important as how people reacts to the new technology accounts for the failure and success of the products. They summarized different ways of how investigators measure innovativeness. Some researchers seek to understand the social phenomenon better and identify the effect of innovativeness on market related issues and portraited the innovativeness as independent variable, moderator or covariate Goldsmith and Foxall (2003). Some emphasize the reliability, generalizability or uniqueness of the construct. And some studied innovativeness for commercial reasons. However, all conceptualization of innovativeness considered the construct as unidimensional and interval measured. In fact, it is true that people react to different innovations differently, and the different reactions consequently impacts their 
adoption decision. And it seemed logical to assume that holding all other variables constant the higher level the innovativeness of the product, the more likely one is to adopt the innovation. But it also makes sense the other way around, in other words, the lower the innovativeness the more likely one is to adopt the innovation. At least it makes sense for my grandma. In addition, it's long been criticized that how should one determine what can be considered as high level of innovativeness. Therefore, in this study, we applied the different technologies as contexts to our survey respondents and tried to figure out if different innovation context would result differently. For instance, both Dyson vacuums (emerging technology) and Google Nest Thermostat (enabling technology) can be considered as highly innovative, should they process similar mechanisms to people's adoption intention? The results of this study suggest that even though they are innovative, people react differently towards them basing on other perceived characteristics of innovation.

\section{Implications}

The implications of this work are clear. If research is aimed at understanding the innovation adoption process, one should consider the effect of social embeddedness, as previously considered important characteristics may no longer holds true under the influence of social embeddedness. As we show in the results, the effects of relative advantage, compatibility and trialability that were related to adoption intention may have little relationship with consumers' decision on whether or not to adopt an innovation. Social embeddedness appears to be related with one's relationship within a social group, as well as with one's reliance on other people. The scale is promising in understanding 
the complex dynamics of social relationships. This work provides empirical evidences that social embeddedness is a valid and reliable impact for innovation diffusion.

This work also has implications for practice, especially for marketing purposes. First, this work provide support that consumers' decision mechanisms have changed compared to before. This study provides a new venue for marketing new innovations depending on the technology type, e.g. through extending social embeddedness. For example, Pixel phones are advertising and extending its social embeddedness by borrowing the popularity, or social embeddedness of iPhone, by comparing the effects of camera shots. Second, this study provides new directions on marketing by showing that except for relative advantage, compatibility and trialability no longer have a strong effect on consumers' adoption intention, thus companies may rearrange the resources on marketing directions.

\section{Limitation}

This study has limitations that needed attention and future research. In this study, we found evidence that social embeddedness correlates with the perceived characteristics and adoption intention towards the innovations. We used the word innovation and product interchangeably. However, innovation correspond to a more general and broader concept, future research may use a more comprehensive definition for innovation.

Second, this is a cross sectional survey study, it would be interesting to find out if the participants had actually adopted the innovation and did it differ from their initial adoption intension, and what may possibly lead to the change. Future studies may use longitudinal, or experimental design to find out the underlying mechanisms of innovation adoption. 
Third, the definition of different types of technologies may be different for the respondents. We tried our best to explain emerging technology and enabling technology to the survey respondents as plain language, and provided them examples enough not to confuse them. But as time goes and technology develops, the definitions may have changed, and a technology previously considered as emerging may progress into an enabling technology rapidly. Although we have not found any statistical evidence for misinterpretation, future research is needed to further clarify different types of technologies.

Fourth, the conclusions drawn from this study could be only one possible explanation towards the phenomena, there could be other underlying mechanisms not illustrated in the study. Future research could perform in-depth interviews to confirm the arguments made in this study. 


\section{CONCLUSION}

Due to the ever-increasing development of technology and social embeddedness, relooking the innovation of diffusion theory has become imperative, both theoretically and practically. Given the context of emerging technology and enabling technology, people reacts differently basing on their level of social embeddedness and their considerations on the perceived characteristics of innovations, while taking the time element into account. Previous literature offers little guidance on measuring time and social system effects in innovation diffusion models, this study offers some insights. The study is theoretically based and are tested empirically. Tech-companies should consider the type of technology and the time of product launch when they are trying to market, in order to impact adoption intention positively, and consequently increase the adoption rate. Social embeddedness is important to all perceived characteristics of innovation. But for adoption of emerging technology, one would consider less of ease of use but more on observability and trialability. While for the adoption of enabling technology, one should focus more on ease of use, but less of observability and trialability. Relative advantage is important for both type of innovations.

This study is one of the first to add time elements for perceived characteristics into innovation diffusion theory models in behavioral research. The aim is to see how the weights for each perceived characteristics of innovation changed over time with the effect of social embeddedness. Since this study is an initial attempt to refine the innovation of diffusion theory, there could be problems and issues unaddressed. But we hope that this study could serve as a stepping stone for future innovation diffusion theory studies. 


\section{LIST OF REFERENCE}

ADANCO. (2019). ADANCO - A modern approach to variance-based structural equation modeling. Retrieved from https://www.composite-modeling.com/

Agarwal, R., \& Prasad, J. (1997). The role of innovation characteristics and perceived voluntariness in the acceptance of information technologies. Decision sciences, 28(3), 557-582.

Ajzen, I. (1985). From intentions to actions: A theory of planned behavior: Springer.

Ajzen, I., \& Fishbein, M. (1980). Understanding attitudes and predicting social behaviour.

Al-Gahtani, S. S. (2003). Computer technology adoption in Saudi Arabia: Correlates of perceived innovation attributes. Information Technology for Development, 10(1), 57-69.

Andridge, R. R., \& Little, R. J. A. (2010). A Review of Hot Deck Imputation for Survey Non-response. International Statistical Review, 78(1), 40-64. doi:10.1111/j.17515823.2010.00103.x

Bass, F. M. (1969). A new product growth for model consumer durables. Management Science, 15(5), 215-227.

Carrus, G., Passafaro, P., \& Bonnes, M. (2008). Emotions, habits and rational choices in ecological behaviours: The case of recycling and use of public transportation. Journal of environmental psychology, 28(1), 51-62.

Cartwright, D., Harary, F., \& Norman, R. (1965). Structural models: An introduction to the theory of directed graphs. New York.

Casaló, L. V., Flavián, C., \& Guinalíu, M. (2010). Determinants of the intention to participate in firm-hosted online travel communities and effects on consumer behavioral intentions. Tourism management, 31(6), 898-911. 
Chiasson, M. W., \& Lovato, C. Y. (2001). Factors influencing the formation of a user's perceptions and use of a DSS software innovation. ACM SIGMIS Database: the DATABASE for Advances in Information Systems, 32(3), 16-35.

Chin, W. W. (1998). The partial least squares approach to structural equation modeling. Modern methods for business research, 295(2), 295-336.

Chin, W. W., \& Newsted, P. R. (1999). Structural equation modeling analysis with small samples using partial least squares. Statistical strategies for small sample research, 1(1), $307-341$.

Dearing, J. W., \& Cox, J. G. (2018). Diffusion Of Innovations Theory, Principles, And Practice. Health Affairs, 37(2), 183-190.

Dee Dickerson, M., \& Gentry, J. W. (1983). Characteristics of adopters and non-adopters of home computers. Journal of Consumer research, 10(2), 225-235.

Diamantopoulos, A., \& Siguaw, J. A. (2006). Formative versus reflective indicators in organizational measure development: A comparison and empirical illustration. British Journal of Management, 17(4), 263-282.

DiMaggio, P. J., \& Powell, W. W. (1991). The new institutionalism in organisational analysis. The new institutionalism in organisational analysis.

Durkheim, E. (2014). The division of labor in society: Simon and Schuster.

Fishbein, M., \& Ajzen, I. (1975). Belief, attitudes, intention, and behavior. An introduction to theory and research. Massachussets: Addison-Wesley.

Fornell, C., \& Larcker, D. F. (1981). Evaluating structural equation models with unobservable variables and measurement error. Journal of Marketing Research, 39-50.

Fornell, C., \& Larcker, D. F. (1981). Structural Equation Models with Unobservable Variables and Measurement Error: Algebra and Statistics. Journal of Marketing Research, 18(3), 382-388. doi:10.1177/002224378101800313 
Fowler, F. J. (2009). Survey Research Methods (4th ed.) Retrieved from https://methods.sagepub.com/book/survey-research-methods

doi:10.4135/9781452230184

Furneaux, B. (2019). Theory of planned behavior. Retrieved from https://is.theorizeit.org/wiki/Theory_of_planned_behavior

Gartner. Gartner Hype Cycle. Retrieved from https://www.gartner.com/technology/research/methodologies/hype-cycle.jsp

Gartner. (1995). Gartner Hype Cycle. Retrieved from

https://www.gartner.com/technology/research/methodologies/hype-cycle.jsp

Gefen, D., Straub, D., \& Boudreau, M.-C. (2000). Structural equation modeling and regression: Guidelines for research practice. Communications of the Association for Information Systems, 4(1), 7.

Granovetter, M. (1985). Economic action and social structure: The problem of embeddedness. American Journal of Sociology, 91(3), 481-510.

Granovetter, M. (1992). Problems of explanation in economic sociology. Networks and organizations: Structure, form, and action, 25, 56.

Harary, F. (1969). Graph theory: Addison-Wesley, Reading, MA.

Henseler, J., Ringle, C. M., \& Sinkovics, R. R. (2009). The use of partial least squares path modeling in international marketing New challenges to international marketing (pp. 277-319): Emerald Group Publishing Limited.

Hsu, S.-H., Chen, W.-H., \& Hsieh, M.-J. (2006). Robustness testing of PLS, LISREL, EQS and ANN-based SEM for measuring customer satisfaction. Total Quality Management \& Business Excellence, 17(3), 355-372.

Katz, E. (1957). The two-step flow of communication: An up-to-date report on an hypothesis. Public opinion quarterly, 21(1), 61-78. 
Kershner, K. (2015). What's the Baader-Meinhof phenomenon? Retrieved from https://science.howstuffworks.com/life/inside-the-mind/human-brain/baader-meinhofphenomenon.htm

Kim, Y., Yun, S., \& Lee, J. (2014). Can companies induce sustainable consumption? The impact of knowledge and social embeddedness on airline sustainability programs in the us. Sustainability, 6(6), 3338-3356.

Kurz, T., Linden, M., \& Sheehy, N. (2007). Attitudinal and community influences on participation in new curbside recycling initiatives in Northern Ireland. Environment and Behavior, 39(3), 367-391.

Linden, A., \& Fenn, J. (2003). Understanding Gartner's hype cycles. Strategic Analysis Report $N^{o}$ R-20-1971. Gartner, Inc.

Lipset, S. M. (1959). Political man: The social bases of politics.

Macneil, I. R. (1985). Relational contract: What we do and do not know. Wis. L. Rev., 483.

Mahajan, V. (1985). Innovation diffusion: Wiley Online Library.

Moore, G. C., \& Benbasat, I. (1991). Development of an instrument to measure the perceptions of adopting an information technology innovation. Information Systems Research, 2(3), 192-222.

Moore, G. C., \& Benbasat, I. (1996). Integrating diffusion of innovations and theory of reasoned action models to predict utilization of information technology by end-users Diffusion and adoption of information technology (pp. 132-146): Springer.

Murray, C. E. (2009). Diffusion of innovation theory: A bridge for the research - practice gap in counseling. Journal of Counseling \& Development, 87(1), 108-116.

O'Leary, D. E. (2008). Gartner's hype cycle and information system research issues. International Journal of Accounting Information Systems, 9(4), 240-252. 
Peres, R., Muller, E., \& Mahajan, V. (2010). Innovation diffusion and new product growth models: A critical review and research directions. International Journal of Research in Marketing, 27(2), 91-106.

Podsakoff, P. M., MacKenzie, S. B., Lee, J.-Y., \& Podsakoff, N. P. (2003). Common method biases in behavioral research: A critical review of the literature and recommended remedies. Journal of applied psychology, 88(5), 879-903. doi:10.1037/0021-9010.88.5.879

Porter, M. E. (1985). Technology and competitive advantage. Journal of business strategy, 5(3), 60-78.

Ratcliffe, S. (2016). Roy Amara 1925-2007, American futurologist. Oxford Essential Quotations (4th ed.): Oxford University Press.

Reed, P. B., \& Selbee, L. K. (2003). Developing and Using Social Embeddedness As an Explanatory Variable. Paper presented at the Annual Conference of the Society for the Advancement of Socio-Economics, Aix-en-Provence, France.

http://www3.carleton.ca/casr/SE.pdf

Rogers, E. M. (2003). Elements of diffusion. Diffusion of innovations, 5(1.38).

Rogers, E. M., \& Shoemaker, F. F. (1971). Communication of Innovations; A CrossCultural Approach.

Rogers Everett, M. (1995). Diffusion of innovations. New York, 12.

Rosenberg, N. (1982). Inside the black box: technology and economics: Cambridge University Press.

Ryan, B., \& Gross, N. C. (1943). The diffusion of hybrid seed corn in two Iowa communities. Rural sociology, 8(1), 15.

Schmidt, A. (2013). Embeddedness. Retrieved from https://www.britannica.com/topic/embeddedness 
Searls, D. (2012). The Intention Economy: When Customers Take Charge: Harvard Business Press.

Simmel, G. (1950). The sociology of georg simmel (Vol. 92892): Simon and Schuster.

Sultan, F., Farley, J. U., \& Lehmann, D. R. (1990). A meta-analysis of applications of diffusion models. Journal of Marketing Research, 27(1), 70-77.

Tornatzky, L. G., \& Klein, K. J. (1982). Innovation characteristics and innovation adoption-implementation: A meta-analysis of findings. IEEE Transactions on engineering management(1), 28-45.

Tucker, C. (2008). Identifying formal and informal influence in technology adoption with network externalities. Management Science, 54(12), 2024-2038.

Utterback, J. M. (1994). Mastering the dynamics of innovation: how companies can seize opportunities in the face of technological change Harvard Business School Press. Boston, $M A$.

Uzzi, B. (1997). Social structure and competition in interfirm networks: The paradox of embeddedness. Administrative science quarterly, 35-67.

Valente, T. W. (1996). Social network thresholds in the diffusion of innovations. Social networks, 18(1), 69-89.

Wear, A. (2008). Innovation and community strength in Provincial Victoria. Australasian Journal of Regional Studies, 14(2), 195.

Weigel, F. K., Hazen, B. T., Cegielski, C. G., \& Hall, D. J. Diffusion of innovations and the theory of planned behavior in information systems research: A metaanalysis.

Weigel, F. K., Hazen, B. T., Cegielski, C. G., \& Hall, D. J. (2014). Diffusion of innovations and the theory of planned behavior in information systems research: A metaanalysis.

Weimann, G. (1982). On the importance of marginality: One more step into the two-step flow of communication. AMERICAN SOCIOLOGICAL REVIEW, 764-773. 
Werts, C. E., Linn, R. L., \& Jöreskog, K. G. (1974). Intraclass Reliability Estimates:

Testing Structural Assumptions. Educational and Psychological Measurement, 34(1), 2533. doi:10.1177/001316447403400104

Zhu, J. J., \& He, Z. (2002). Perceived characteristics, perceived needs, and perceived popularity: Adoption and use of the Internet in China. Communication research, 29(4), 466-495.

Zwicky. (2005). Just Between Dr. Language and I. Language Log. Retrieved from http://itre.cis.upenn.edu/ myl/languagelog/archives/002386.html 


\title{
Innovation Diffusion Theory and Social Embeddedness -A New Perspective
}

\author{
Survey Questions
}

Thank you for your participation. This survey will take approximately 10 mins to complete. All records associated with this study will be kept confidential.

Please answer the following questions using the information and definitions we provide to you.

\section{Case Scenario 1 for Emerging Technology Adoption}

We define an emerging technology as a radically novel and relatively fast-growing technology with the potential to exert a considerable influence on society. Most of its influence lies in the future and so it is still somewhat uncertain and ambiguous.

For example, Dyson is a product innovator that follows a radical, emerging technology approach to its product offerings. Dyson has gone through the process of reinventing often overlooked categories of domestic appliances such as the vacuum and fan. They have delivered market innovation and influence through their technology. Other examples of emerging technologies include the Apple watch and the Amazon dash button.

The following questions are focused on your experience with emerging technology. Using the definition and examples above, please recall some emerging technologies you may have considered to adopt and why you decided (or not) to adopt the them. 
Q1. Please identify and briefly describe the emerging technology example(s) you have in mind?

Q2. Perceived characteristics on innovation

\begin{tabular}{|c|c|c|c|c|c|c|c|c|}
\hline Construct & Survey Question Items & $\begin{array}{l}\text { Strongly } \\
\text { Disagree }\end{array}$ & $\begin{array}{l}\text { Mostly } \\
\text { Disagree }\end{array}$ & $\begin{array}{l}\text { Somewhat } \\
\text { Disagree }\end{array}$ & Neutral & $\begin{array}{c}\text { Somewhat } \\
\text { Agree }\end{array}$ & $\begin{array}{l}\text { Mostly } \\
\text { Agree }\end{array}$ & $\begin{array}{l}\text { Strongly } \\
\text { Agree }\end{array}$ \\
\hline \multirow{4}{*}{ 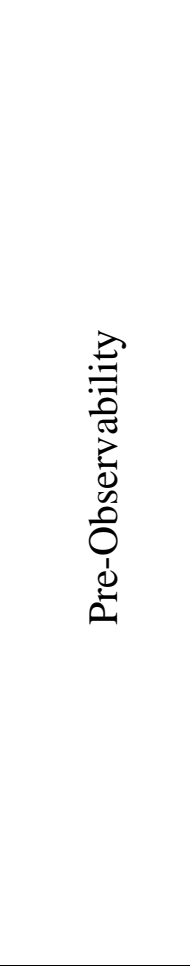 } & $\begin{array}{l}\text { I have read what others think } \\
\text { about using the emerging } \\
\text { technology before it was } \\
\text { available to the public (such } \\
\text { as online text reviews, } \\
\text { opinions, news etc.). }\end{array}$ & $\mathrm{O}$ & $\mathrm{O}$ & 0 & $\mathrm{O}$ & $\mathrm{O}$ & $\mathrm{O}$ & O \\
\hline & $\begin{array}{l}\text { It is easy for me to see others } \\
\text { using the emerging } \\
\text { technology before it was } \\
\text { available to the public (such } \\
\text { as video reviews, prototypes } \\
\text { etc.). }\end{array}$ & 0 & 0 & 0 & 0 & 0 & 0 & 0 \\
\hline & $\begin{array}{l}\text { I have had plenty of } \\
\text { opportunity to see the } \\
\text { emerging technology (such as } \\
\text { ads etc.) before it was } \\
\text { available to the public. }\end{array}$ & 0 & 0 & 0 & 0 & 0 & 0 & $\mathrm{O}$ \\
\hline & $\begin{array}{l}\text { Video, reviews and } \\
\text { demonstrations of the }\end{array}$ & 0 & O & $\mathrm{O}$ & $\mathrm{O}$ & 0 & $\mathrm{O}$ & 0 \\
\hline
\end{tabular}




\begin{tabular}{|c|c|c|c|c|c|c|c|c|}
\hline & $\begin{array}{l}\text { emerging technology are } \\
\text { often seen within my social } \\
\text { group before the emerging } \\
\text { technology was available to } \\
\text { the public. }\end{array}$ & & & & & & & \\
\hline \multirow{4}{*}{ 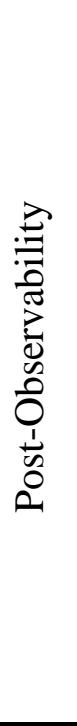 } & $\begin{array}{l}\text { I have seen the emerging } \\
\text { technology in use by my } \\
\text { friends and acquaintances. }\end{array}$ & 0 & 0 & O & 0 & 0 & 0 & 0 \\
\hline & $\begin{array}{l}\text { The emerging technology is } \\
\text { very visible amongst my } \\
\text { friends and acquaintances. }\end{array}$ & 0 & 0 & 0 & 0 & 0 & O & 0 \\
\hline & $\begin{array}{l}\text { It is easy for me to observe } \\
\text { others using the emerging } \\
\text { technology after it is made } \\
\text { available to the public. }\end{array}$ & 0 & 0 & 0 & 0 & 0 & 0 & 0 \\
\hline & $\begin{array}{l}\text { I had plenty of opportunity to } \\
\text { see the emerging technology } \\
\text { being used after it was } \\
\text { available to the public. }\end{array}$ & O & 0 & O & O & 0 & $O$ & 0 \\
\hline \multirow[t]{2}{*}{ 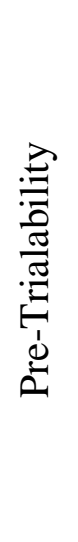 } & $\begin{array}{l}\text { I had plenty of opportunity to } \\
\text { try out the emerging } \\
\text { technology myself before it } \\
\text { was available to the public } \\
\text { (such as prototypes, trail } \\
\text { versions, beta versions, in- } \\
\text { store experience, showrooms } \\
\text { etc.). }\end{array}$ & 0 & $O$ & 0 & 0 & 0 & $\mathrm{O}$ & 0 \\
\hline & $\begin{array}{l}\text { I know where I can go to try } \\
\text { out the emerging technology } \\
\text { myself before it was available }\end{array}$ & 0 & O & 0 & 0 & 0 & 0 & 0 \\
\hline
\end{tabular}




\begin{tabular}{|c|c|c|c|c|c|c|c|c|}
\hline & $\begin{array}{l}\text { to the public (such as stores } \\
\text { providing in store experience, } \\
\text { Apple, Tesla, etc.). }\end{array}$ & & & & & & & \\
\hline \multirow{2}{*}{ 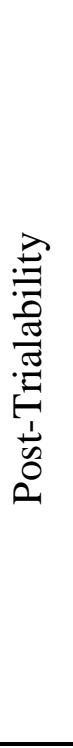 } & $\begin{array}{l}\text { I have had a great deal of } \\
\text { opportunity to try out the } \\
\text { emerging technology after it } \\
\text { was available to the public } \\
\text { (through your friends who } \\
\text { own the technology, stores } \\
\text { that sell the technology etc.). }\end{array}$ & 0 & 0 & 0 & O & 0 & O & 0 \\
\hline & $\begin{array}{l}\text { I know friends and } \\
\text { acquaintances who tried out } \\
\text { the emerging technology } \\
\text { after it was available to the } \\
\text { public (through your friends } \\
\text { who own the technology, } \\
\text { stores that sell the technology } \\
\text { etc.). }\end{array}$ & 0 & 0 & O & 0 & 0 & $\mathrm{O}$ & 0 \\
\hline \multirow{3}{*}{ 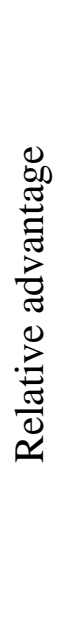 } & $\begin{array}{l}\text { Using the emerging } \\
\text { technology helps me to } \\
\text { accomplish tasks more } \\
\text { quickly compared with its } \\
\text { competitors. }\end{array}$ & 0 & 0 & $\mathrm{O}$ & 0 & 0 & 0 & 0 \\
\hline & $\begin{array}{l}\text { Using the emerging } \\
\text { technology improves the } \\
\text { quality of my life or work } \\
\text { compared with its } \\
\text { competitors. }\end{array}$ & 0 & 0 & 0 & 0 & 0 & 0 & 0 \\
\hline & $\begin{array}{l}\text { Using the emerging } \\
\text { technology makes my life or }\end{array}$ & O & 0 & O & 0 & 0 & O & 0 \\
\hline
\end{tabular}




\begin{tabular}{|c|c|c|c|c|c|c|c|c|}
\hline & $\begin{array}{l}\text { work easier compared with its } \\
\text { competitors. }\end{array}$ & & & & & & & \\
\hline & $\begin{array}{l}\text { The advantages of my using } \\
\text { the emerging technology far } \\
\text { outweigh the disadvantages. }\end{array}$ & 0 & 0 & 0 & O & 0 & O & 0 \\
\hline & $\begin{array}{l}\text { Overall, I find using the } \\
\text { emerging technology to be } \\
\text { advantageous. }\end{array}$ & 0 & 0 & 0 & O & 0 & 0 & 0 \\
\hline & $\begin{array}{l}\text { Using the emerging } \\
\text { technology gives me greater } \\
\text { control over my work or life } \\
\text { compared with its } \\
\text { competitors. }\end{array}$ & 0 & 0 & 0 & O & 0 & O & 0 \\
\hline \multirow{4}{*}{ 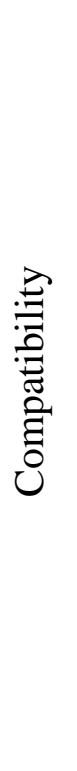 } & $\begin{array}{l}\text { Using the emerging } \\
\text { technology is compatible with } \\
\text { my work or life. }\end{array}$ & 0 & $O$ & 0 & O & 0 & O & 0 \\
\hline & $\begin{array}{l}\text { I think that using the } \\
\text { emerging technology fits well } \\
\text { with the way I think about } \\
\text { things. }\end{array}$ & 0 & 0 & 0 & O & 0 & O & $O$ \\
\hline & $\begin{array}{l}\text { The emerging technology is } \\
\text { compatible with other } \\
\text { technologies I am currently } \\
\text { using. }\end{array}$ & 0 & 0 & 0 & O & 0 & 0 & 0 \\
\hline & $\begin{array}{l}\text { The emerging technology } \\
\text { does not require much effort } \\
\text { to switch from my previous } \\
\text { technologies. }\end{array}$ & 0 & 0 & 0 & O & 0 & O & 0 \\
\hline
\end{tabular}




\begin{tabular}{|c|c|c|c|c|c|c|c|c|}
\hline \multirow{4}{*}{ 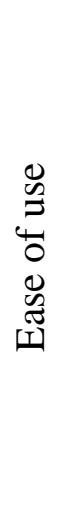 } & $\begin{array}{l}\text { I believe that the emerging } \\
\text { technology is easy to use. }\end{array}$ & O & 0 & 0 & 0 & 0 & 0 & 0 \\
\hline & $\begin{array}{l}\text { It is easy for me to remember } \\
\text { how to perform tasks using } \\
\text { the emerging technology. }\end{array}$ & 0 & 0 & O & 0 & 0 & 0 & 0 \\
\hline & $\begin{array}{l}\text { My typical interactions with } \\
\text { the emerging technology are } \\
\text { clear and understandable. }\end{array}$ & 0 & O & O & 0 & 0 & 0 & 0 \\
\hline & $\begin{array}{l}\text { Learning to use the emerging } \\
\text { technology is easy for me. }\end{array}$ & 0 & 0 & 0 & 0 & 0 & 0 & 0 \\
\hline
\end{tabular}

Q3. Adoption Intention (reflective)

\begin{tabular}{|c|l|c|c|c|c|c|c|c|}
\hline Construct & Survey Question Items & $\begin{array}{l}\text { Strongly } \\
\text { Disagree }\end{array}$ & $\begin{array}{l}\text { Mostly } \\
\text { Disagree }\end{array}$ & $\begin{array}{l}\text { Somewhat } \\
\text { Disagree }\end{array}$ & Neutral & $\begin{array}{l}\text { Somewhat } \\
\text { Agree }\end{array}$ & $\begin{array}{l}\text { Mostly } \\
\text { Agree }\end{array}$ & $\begin{array}{l}\text { Strongl } \\
\text { y Agree }\end{array}$ \\
\hline & $\begin{array}{l}\text { I intend to (or I did) adopt the } \\
\text { emerging technology when it } \\
\text { is available. }\end{array}$ & 0 & 0 & 0 & 0 & 0 & 0 & 0 \\
\cline { 2 - 6 } & $\begin{array}{l}\text { I will consider (or I did } \\
\text { consider) adopting the } \\
\text { emerging technology when } \\
\text { the opportunity presents itself. }\end{array}$ & 0 & 0 & 0 & 0 & 0 & 0 & 0 \\
& $\begin{array}{l}\text { I plan to adopt the emerging } \\
\text { technology (or similar } \\
\text { technologies) in the future. }\end{array}$ & 0 & 0 & 0 & 0 & 0 & 0 & 0 \\
\hline
\end{tabular}


Q4. Social Embeddedness (formative)

\begin{tabular}{|c|c|c|c|c|c|c|c|c|}
\hline Construct & Survey Question Items & $\begin{array}{l}\text { Strongly } \\
\text { Disagree }\end{array}$ & $\begin{array}{l}\text { Mostly } \\
\text { Disagree }\end{array}$ & $\begin{array}{l}\text { Somewhat } \\
\text { Disagree }\end{array}$ & Neutral & $\begin{array}{l}\text { Somewhat } \\
\text { Agree }\end{array}$ & $\begin{array}{l}\text { Mostly } \\
\text { Agree }\end{array}$ & $\begin{array}{l}\text { Strongly } \\
\text { Agree }\end{array}$ \\
\hline \multirow{4}{*}{ 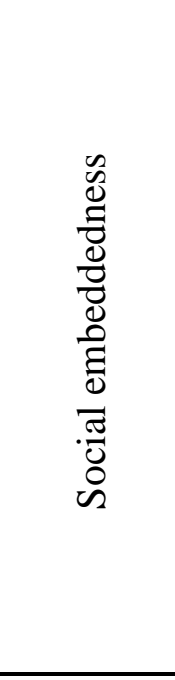 } & $\begin{array}{l}\text { My relationships and } \\
\text { interactions with people } \\
\text { outside my family members } \\
\text { are generally good. }\end{array}$ & $\mathrm{O}$ & $\mathrm{O}$ & $\mathrm{O}$ & $\mathrm{O}$ & $\mathrm{O}$ & $\mathrm{O}$ & $\mathrm{O}$ \\
\hline & $\begin{array}{l}\text { My relationships and } \\
\text { interactions with neighbors } \\
\text { and coworkers are generally } \\
\text { good. }\end{array}$ & $\mathrm{O}$ & $\mathrm{O}$ & $\mathrm{O}$ & $\mathrm{O}$ & $\mathrm{O}$ & O & O \\
\hline & $\begin{array}{l}\text { I participate in charitable } \\
\text { giving and volunteering. }\end{array}$ & $\mathrm{O}$ & $\mathrm{O}$ & $\mathrm{O}$ & O & O & $\mathrm{O}$ & O \\
\hline & $\begin{array}{l}\text { I have a strong sense of } \\
\text { belongingness and attachment } \\
\text { to my community. }\end{array}$ & $\mathrm{O}$ & O & $\mathrm{O}$ & $\mathrm{O}$ & $\mathrm{O}$ & O & O \\
\hline
\end{tabular}

\section{Question on respondents}

The following questions are about your general information.

Gender:

O Male (1)

Female (2) 
Age Group:

O $18-25(1)$

O $26-40(2)$

O $41-59$ (3)

O $60+$

Ethnicity:

O African American (1)

O American Indian or Alaska Native (2)

O Asian (3)

Native Hawaiian or Pacific Islander (4)

O Caucasian (5)

O Hispanic or Latino (6)

O Middle Eastern

Education:

What is the highest level of education you have achieved so far?

High School

O Some College

O Bachelor's Degree

O Some graduate school

O Master's Degree

Doctoral Degree 


\section{Case Scenario 2 for Enabling Technology Adoption}

We define enabling technology as either relatively simple extensions or modifications to existing products or technologies that result in a new way to do old things or may provide a vehicle for new opportunities. Enabling technologies can often be realized by combining existing technologies to create something entirely new.

For example, combining the Internet and a simple computer with a common gasoline pump to create a smart pump.

The following questions are associated with your experience with an enabling technology. Please recall one or more enabling technologies you considered to adopt (or ultimately did adopt), and why you decided (or not) to adopt them.

Q1. What enabling technology examples are you thinking about?

Q2. Perceived characteristics on innovation

\begin{tabular}{|c|c|c|c|c|c|c|c|c|}
\hline Construct & Survey Question Items & $\begin{array}{l}\text { Strongly } \\
\text { Disagree }\end{array}$ & $\begin{array}{l}\text { Mostly } \\
\text { Disagree }\end{array}$ & $\begin{array}{l}\text { Somewhat } \\
\text { Disagree }\end{array}$ & Neutral & $\begin{array}{c}\text { Somewhat } \\
\text { Agree }\end{array}$ & $\begin{array}{l}\text { Mostly } \\
\text { Agree }\end{array}$ & $\begin{array}{l}\text { Strongly } \\
\text { Agree }\end{array}$ \\
\hline \multirow{2}{*}{ 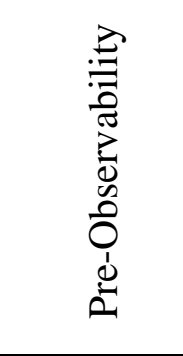 } & $\begin{array}{l}\text { I have read what others think about } \\
\text { using the enabling technology } \\
\text { before it was available to the public } \\
\text { (such as online text reviews, } \\
\text { opinions, news etc.). }\end{array}$ & $\mathrm{O}$ & $\mathrm{O}$ & $\mathrm{O}$ & $\mathrm{O}$ & $\mathrm{O}$ & $\mathrm{O}$ & $\mathrm{O}$ \\
\hline & $\begin{array}{l}\text { It is easy for me to observe others } \\
\text { using the enabling technology }\end{array}$ & $\mathrm{O}$ & O & $\mathrm{O}$ & O & $\mathrm{O}$ & $\mathrm{O}$ & $\mathrm{O}$ \\
\hline
\end{tabular}




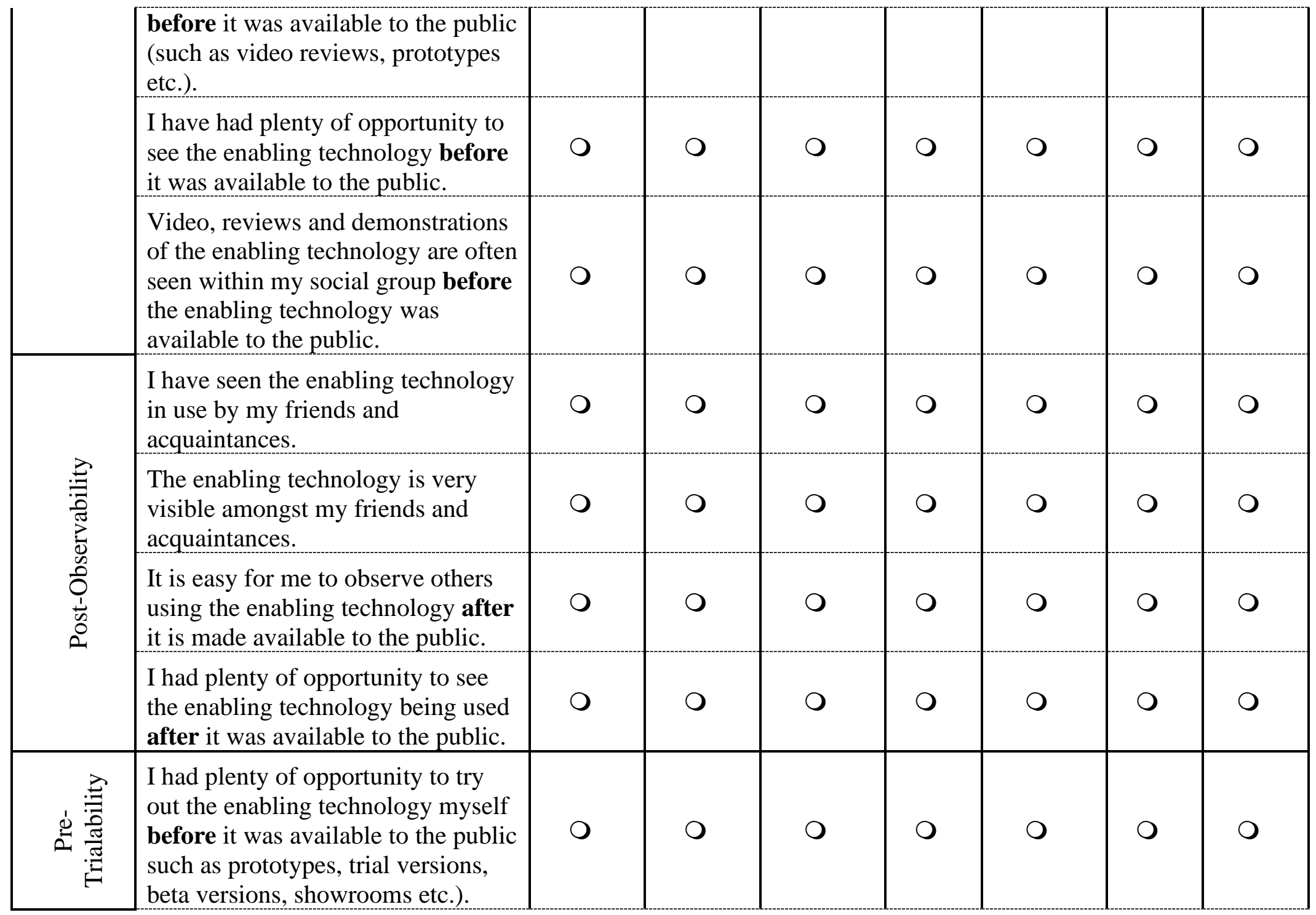




\begin{tabular}{|c|c|c|c|c|c|c|c|c|}
\hline & $\begin{array}{l}\text { I know friends and acquaintances } \\
\text { who tried out the enabling } \\
\text { technology myself before it was } \\
\text { available to the public (such as tech } \\
\text { expo events, exhibitions, } \\
\text { showrooms etc.). }\end{array}$ & 0 & 0 & 0 & 0 & 0 & 0 & 0 \\
\hline \multirow{2}{*}{ 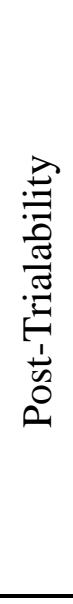 } & $\begin{array}{l}\text { I have had a great deal of } \\
\text { opportunity to try out the enabling } \\
\text { technology after it was available to } \\
\text { the public (through your friends } \\
\text { who own the technology, stores that } \\
\text { sell the technology etc.). }\end{array}$ & $O$ & 0 & 0 & 0 & 0 & 0 & 0 \\
\hline & $\begin{array}{l}\text { I know friends and acquaintances } \\
\text { who tried out the enabling } \\
\text { technology after it was available to } \\
\text { the public (through your friends } \\
\text { who own the technology, stores that } \\
\text { sell the technology etc.). }\end{array}$ & O & 0 & 0 & 0 & $O$ & 0 & 0 \\
\hline \multirow{3}{*}{ 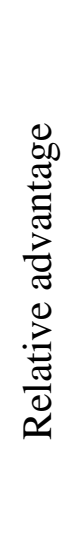 } & $\begin{array}{l}\text { Using the enabling technology } \\
\text { helps me to accomplish tasks more } \\
\text { quickly compared with its } \\
\text { competitors. }\end{array}$ & $O$ & O & 0 & 0 & 0 & 0 & 0 \\
\hline & $\begin{array}{l}\text { Using the enabling technology } \\
\text { improves the quality of my life or } \\
\text { work compared with its } \\
\text { competitors. }\end{array}$ & $\mathrm{O}$ & 0 & 0 & 0 & 0 & 0 & 0 \\
\hline & $\begin{array}{l}\text { Using the enabling technology } \\
\text { makes my life or work easier } \\
\text { compared with its competitors. }\end{array}$ & O & 0 & 0 & 0 & 0 & 0 & 0 \\
\hline
\end{tabular}




\begin{tabular}{|c|c|c|c|c|c|c|c|c|}
\hline & $\begin{array}{l}\text { The advantages of my using the } \\
\text { enabling technology far outweigh } \\
\text { the disadvantages. }\end{array}$ & O & O & O & $\mathrm{O}$ & $\mathrm{O}$ & $\mathrm{O}$ & 0 \\
\hline & $\begin{array}{l}\text { Overall, I find using the enabling } \\
\text { technology to be advantageous. }\end{array}$ & 0 & 0 & 0 & 0 & $\mathrm{O}$ & 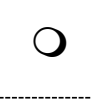 & O \\
\hline & $\begin{array}{l}\text { Using the enabling technology } \\
\text { gives me greater control over my } \\
\text { work or life compared with its } \\
\text { competitors. }\end{array}$ & 0 & 0 & 0 & $\mathrm{O}$ & $O$ & 0 & 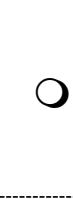 \\
\hline \multirow{4}{*}{ 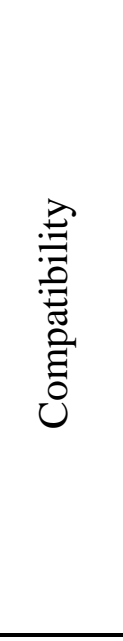 } & $\begin{array}{l}\text { Using the enabling technology is } \\
\text { compatible with all aspects of my } \\
\text { work or life. }\end{array}$ & O & 0 & O & $\mathrm{O}$ & $\mathrm{O}$ & 0 & 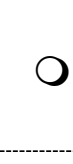 \\
\hline & $\begin{array}{l}\text { I think that using the enabling } \\
\text { technology fits well with the way I } \\
\text { think about things. }\end{array}$ & $O$ & 0 & 0 & O & $\mathrm{O}$ & $\mathrm{O}$ & 0 \\
\hline & $\begin{array}{l}\text { The enabling technology is } \\
\text { compatible with other technologies } \\
\text { I am currently using. }\end{array}$ & $O$ & O & $\mathrm{O}$ & $\mathrm{O}$ & $\mathrm{O}$ & $\mathrm{O}$ & $O$ \\
\hline & $\begin{array}{l}\text { The enabling technology does not } \\
\text { require much effort to switch from } \\
\text { my previous technologies. }\end{array}$ & O & 0 & O & $\mathrm{O}$ & $\mathrm{O}$ & $\mathrm{O}$ & 0 \\
\hline \multirow{3}{*}{ 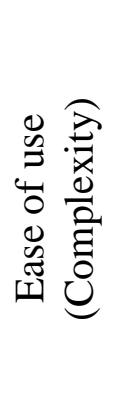 } & $\begin{array}{l}\text { I believe that the enabling } \\
\text { technology is easy to use. }\end{array}$ & $\mathrm{O}$ & O & $\mathrm{O}$ & O & $\mathrm{O}$ & $\mathrm{O}$ & 0 \\
\hline & $\begin{array}{l}\text { It is easy for me to remember how } \\
\text { to perform tasks using the enabling } \\
\text { technology. }\end{array}$ & 0 & 0 & 0 & O & $O$ & 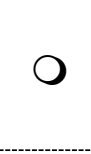 & O \\
\hline & $\begin{array}{l}\text { My typical interactions with the } \\
\text { enabling technology are clear and } \\
\text { understandable. }\end{array}$ & 0 & 0 & O & O & 0 & 0 & 0 \\
\hline
\end{tabular}


Learning to use the enabling

technology is easy for me.

\begin{tabular}{l|l}
\hline 0 & 0 \\
\hline
\end{tabular}

O

\begin{tabular}{|l|l|l|l|}
\hline 0 & 0 & 0 & 0 \\
\hline
\end{tabular}

Q3. Adoption Intention

\begin{tabular}{|c|l|c|c|c|c|c|c|c|}
\hline Construct & Survey Question Items & $\begin{array}{c}\text { Strongly } \\
\text { Disagree }\end{array}$ & $\begin{array}{c}\text { Mostly } \\
\text { Disagree }\end{array}$ & $\begin{array}{c}\text { Somewhat } \\
\text { Disagree }\end{array}$ & Neutral & $\begin{array}{c}\text { Somewhat } \\
\text { Agree }\end{array}$ & $\begin{array}{c}\text { Mostly } \\
\text { Agree }\end{array}$ & $\begin{array}{c}\text { Strongly } \\
\text { Agree }\end{array}$ \\
\hline & $\begin{array}{l}\text { I intend to (or I did) adopt the } \\
\text { enabling technology when it } \\
\text { is available. }\end{array}$ & 0 & 0 & 0 & 0 & 0 & 0 & 0 \\
\cline { 1 - 2 } & $\begin{array}{l}\text { I will consider (or I did } \\
\text { consider) adopting the } \\
\text { enabling technology when the } \\
\text { opportunity presents itself. }\end{array}$ & 0 & 0 & 0 & 0 & 0 & 0 & 0 \\
& $\begin{array}{l}\text { I plan to adopt the enabling } \\
\text { technology (or similar } \\
\text { technologies) in the future. }\end{array}$ & 0 & 0 & 0 & 0 & 0 & 0 & 0 \\
\hline
\end{tabular}

Q4. Social Embeddedness

\begin{tabular}{|c|c|c|c|c|c|c|c|c|}
\hline Construct & Survey Question Items & $\begin{array}{l}\text { Strongly } \\
\text { Disagree }\end{array}$ & $\begin{array}{c}\text { Mostly } \\
\text { Disagree }\end{array}$ & $\begin{array}{l}\text { Somewhat } \\
\text { Disagree }\end{array}$ & Neutral & $\begin{array}{c}\text { Somewhat } \\
\text { Agree }\end{array}$ & $\begin{array}{l}\text { Mostly } \\
\text { Agree }\end{array}$ & $\begin{array}{c}\text { Strongly } \\
\text { Agree }\end{array}$ \\
\hline \multirow{2}{*}{ 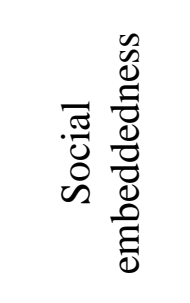 } & $\begin{array}{l}\text { My relationships and } \\
\text { interactions with people } \\
\text { outside my family members } \\
\text { are generally good. }\end{array}$ & O & O & O & O & O & 0 & 0 \\
\hline & $\begin{array}{l}\text { My relationships and } \\
\text { interactions with neighbors }\end{array}$ & O & 0 & O & O & 0 & 0 & 0 \\
\hline
\end{tabular}




\begin{tabular}{|c|c|c|c|c|c|c|c|}
\hline $\begin{array}{l}\text { and coworkers are generally } \\
\text { good. }\end{array}$ & & & & & & & \\
\hline $\begin{array}{l}\text { I participate in charitable } \\
\text { giving and volunteering. }\end{array}$ & 0 & O & 0 & 0 & 0 & O & 0 \\
\hline $\begin{array}{l}\text { I have a strong sense of } \\
\text { belongingness and attachment } \\
\text { to my community. }\end{array}$ & O & 0 & O & 0 & 0 & 0 & 0 \\
\hline
\end{tabular}

\section{Question on respondents}

The following questions are about your general information.

Gender:

O Male (1)

O Female (2)

Age Group:

O $18-25(1)$

O $26-40(2)$

O $41-59$ (3)

O $60+$ 


\section{Ethnicity:}

African American (1)

O American Indian or Alaska Native (2)

O Asian (3)

Native Hawaiian or Pacific Islander (4)

O Caucasian (5)

O Hispanic or Latino (6)

O Middle Eastern

\section{Education:}

What is the highest level of education you have achieved so far?

\section{High School}

O Some College

O Bachelor's Degree

Some graduate school

O Master's Degree

Doctoral Degree 


\section{XUAN TAN}

2009-2013

B.A., Accounting

Central South University

Changsha, Hunan, China

2013-2014

M.S.C Business Analytics: Operational Research and Risk Analysis

The University of Manchester

Manchester, UK

2015-

Doctoral Candidate

Florida International University

Miami, Florida, USA

\section{PUBLICATIONS AND PRESENTATIONS}

Min Chen, Sheng Guo, and Xuan Tan. "Does Health Information Exchange Improve Patient Outcomes? Empirical Evidence From Florida Hospitals." Health Affairs 38.2 (2019): 197-204.

Min Chen, Rema Padman, Jana Macickova, Xuan Tan, Manjiri Kshirsagar, Ashita Vadlamudi, Chi Zhang; Using Social Determinants of Health to Predict Health Outcomes; The Institute for Operations Research and the Management Sciences (INFORMS) Healthcare Conference 2019; July $27^{\text {th }}-29^{\text {th }}$, 2019; Cambridge, MA, USA.

Min Chen, Sheng Guo, Xuan Tan; Does Health Information Exchange Improve Patient Outcomes? Empirical Evidence from a Longitudinal Study; Production and Operations Management Society (POMS) $29^{\text {th }}$ Annual Conference; May $4^{\text {th }}-7^{\text {th }} 2018$; Houston, TX, USA.

Hyeyoung Hah, Xuan Tan, Manjul Gupta; Health Consumers, Information Search: Daily Search Triggers and Preferred Media Capability; $24^{\text {th }}$ Americas Conference on Information Systems (AMCIS); August $16^{\text {th }}-18^{\text {th }} 2018$; New Orleans, LA, USA. 
Min Chen, Sheng Guo, Xuan Tan; Does Health Information Exchange Improve Patient Outcomes? Empirical Evidence from Florida Hospitals; Conference on Health It and Analytics (CHITA); November $3^{\text {rd }}-4^{\text {th }}$ 2017; Washington, DC, USA.

Weidong Xia, Malgorzata Kolotylo, Xuan Tan; Factors Affecting General Practitioners' Transfer of Specialized Self-care Knowledge to Patients; ICKMI $2016: 18^{\text {th }}$ International Conference on Knowledge Management and Innovation; October $10^{\text {th }}-11^{\text {th }}, 2016$; New York, USA.

Xuan Tan, Karlene C. Cousins; Herding Behavior in Social Media Networks in China (Emergent Research Forum Papers); $22^{\text {nd }}$ Americas Conference on Information Systems (AMCIS); August $11^{\text {th }}-14^{\text {th }}$ 2016; San Diego, CA, USA. 